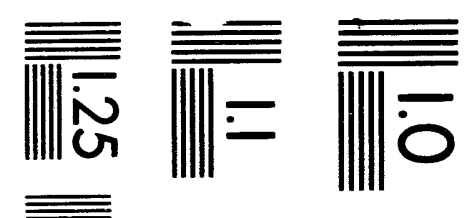

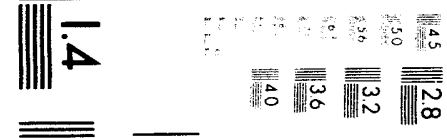

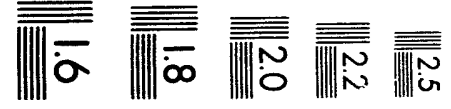



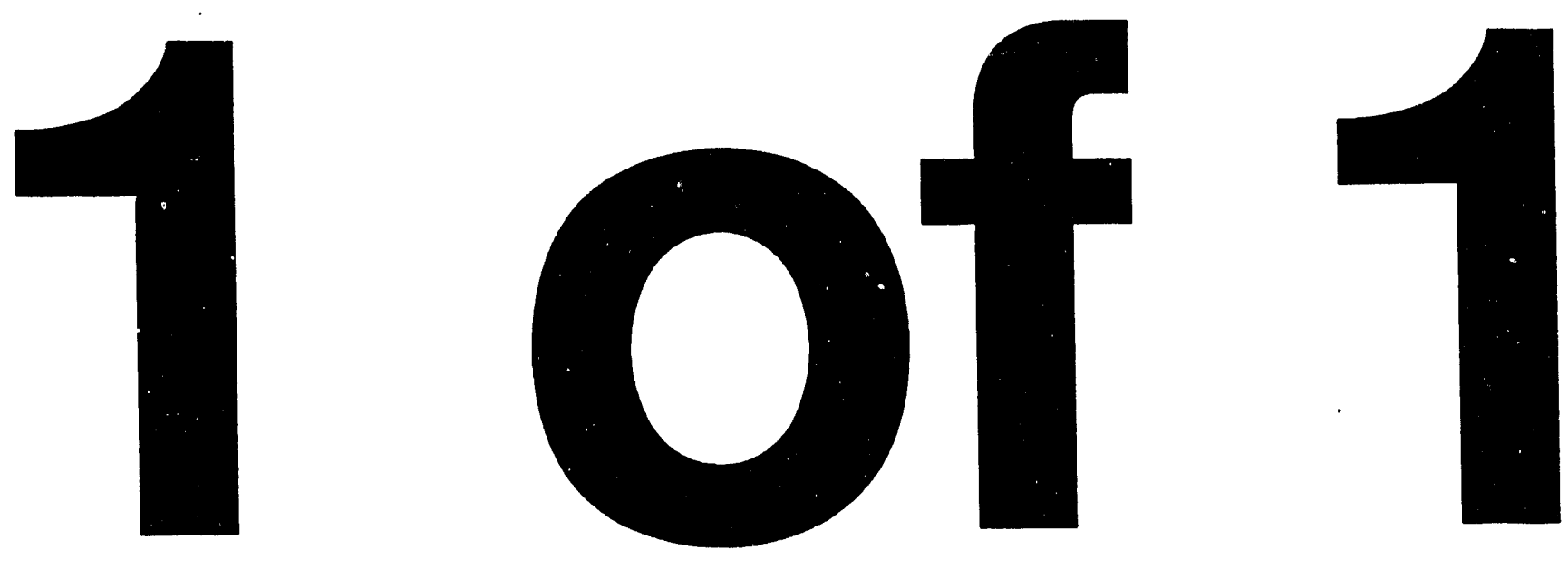


\title{
TECHNOLOGY DEVELOPMENT FOR IRON FISCHER-TROPSCH CATALYSTS
}

\author{
CONTRACT DE-AC22-90PC90055
}

\author{
Technical Progress Report No. 9 \\ 9/26/92-12/26/92
}

\author{
prepared for \\ Pittsburgh Energy Technology Center \\ Department of Energy \\ Pittsburgh. Penncvlvania \\ DISCLAIMER
}

\begin{abstract}
This report was prepared as an account of work sponsored by an agency of the United States Government. Neither the United States Government nor any agency thereof, nor any of their employees, makes any warranty, express or implied, or assumes any legal liability or responsibility for the accuracy, completeness, or usefulness of any information, apparatus, product, or process disclosed, or represents that its use would not infringe privately owned rights. Reference herein to any specific commercial product, process, or service by trade name, trademark, manufacturer, or otherwise does not necessarily constitute or imply its endorsement, recommendation, or favoring by the United States Government or any agency thereof. The views and opinions of authors expressed herein do not necessarily state or reflect those of the United States Government or any agency thereof.
\end{abstract}

prepared by

\section{UOP}

25 E. Algonquin Road Des Plaines, nlinois

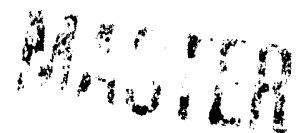

i

$\operatorname{coc} 9:$ Nivimibr 15,1993 
Contract No. DE-AC22-90PC90055

Robert R. Frame and Hemant B. Gala

UOP

25 E. Algonquin Road

Des Plaines, Illinois

Technical Progress Report No. 9

$(9 / 26 / 92-12 / 26 / 92)$

\section{Contract Objective}

The objectives of this contract are to develop a technology for the production of active and stable iron (Fe) Fischer-Tropsch catalysts for use in slurry-phase synthesis reactors and to develop a scaleup procedure for large-scale synthesis of such catalysts for process development and long-term testing in slurry bubble-column reactors. With a feed containing hydrogen $\left(\mathrm{H}_{2}\right)$ and carbon monoxide (CO) in the molar ratio of 0.5 to 1.0 to the slurry bubble-column reactor, the catalyst performance target is $88 \% \mathrm{CO}+\mathrm{H}_{2}$ conversion at a minimum space velocity of $2.4 \mathrm{NL} / \mathrm{hr} / \mathrm{gFe}$. The desired sum of methane and ethane selectivities is no more than $4 \%$, and the conversion loss per week is not to exceed $1 \%$.

\section{Contract Tasks}

Task 1.0: Catalyst development

1.1: Technology assessment

1.2: Precipitated catalyst preparation method development

1.3: Novel catalyst preparation methods investigation

1.4: Catalyst pretreatment

1.5: Catalyst characterization

Task 2.0: Catalyst testing

Task 3.0: Catalyst aging studies

Task 4.0: Preliminary design and cost estimate of a catalyst synthesis facility

\section{Experimental}

A slurry autoclave pilot plant is used for catalyst evaluations, the autoclave of which is contained in a $130^{\circ} \mathrm{C}$ hot box. The liquid and gaseous products are separately withdrawn but taken to the same traps. There are three traps in series, the first is in the hot box, the second and third are outside of the hot box and maintained at ice and dry ice/acetone temperatures respectively. A small slip stream of the product before the ice trap is taken to a gas chromatograph (GC-1) for an on-line boiling point type of analysis. A second slip stream (after the ice trap) is taken to a second GC (GC-2) for an analysis for gases $\left(C_{1}-C_{4}\right)$. 


\section{Scope of the Work during the Reporting Period}

\section{Task 1.3}

In iron-based Fischer-Tropsch (F-T) catalysts potassium is added to increase the catalyst activity and decrease the light ends selectivities. The amount of potassium added is critical because past a certain level further additions of potassium cause a loss in activity. A new method of adding potassium to a slurry phase F-T catalyst was described in Quarterly Report No. 8 of this contract. In this new method a potassium salt of a long-chain carboxylic acid (e.g. potassium laurate) is added to a mixture of the ironcopper oxide catalyst precursor and an oil (typically a $\mathrm{C}_{30}$ oil) in a slurry autoclave. The resulting mixture is activated by a standard method to produce a slurry-phase Fischer-Tropsch catalyst. In performance such a catalyst exhibits $\mathrm{H}_{2}$ and $\mathrm{CO}$ conversions and product selectivities comparable to a catalyst prepared by the historic method (e.g. aqueous impregnation of the iron-copper oxide with potassium carbonate followed by calcination). In this report a new way of adding potassium laurate is described in which a solution of potassium laurate in a mixture of isopropanol and heptane is pumped into the slurry autoclave reactor during a run. One advantage from using a solution of the potassium salt is that it provides a way to add potassium during, instead of only before, a run. With this method, for instance, potassium can be added in increments to "fine tune" cataiyst performance.

\section{Run 46}

In this run $73 \mathrm{~g}$ of a potassium-free iron-copper oxide (Catalyst 6616-189) was added to the slurry autoclave reactor along with $290 \mathrm{~g}$ of a $\mathrm{C}_{30}$ oil. Properties of this catalyst are summarized in Table 1 . Catalyst activation was by treatment with the feed $\left(0.7\right.$ molar ratio of $\left.\mathrm{H}_{2}: \mathrm{CO}\right)$ at the rate of 2.0 $\mathrm{NL} / \mathrm{Hr} \cdot \mathrm{g} \mathrm{Fe}$ at $153 \mathrm{psig}$ and $280^{\circ} \mathrm{C}$ for 24 hours. Following activation, the conditions were: feed, 2.3 $\mathrm{NL} / \mathrm{hr} \cdot \mathrm{g} \mathrm{Fe}, 290 \mathrm{psig}$ and $265^{\circ} \mathrm{C}$. Plots of conversions and selectivities as a function of hours-on-stream are in Appendix 1 as Figures A-1 to A- 10. The initial CO conversion was $10 \%$ increasing to $20 \%$ at line-out (175 hours on stream). A low conversion from a potassium-free catalyst with such an activation procedure was not unexpected. At 175 hours a second feed was added via the second feed line. This feed was a $50: 50$ (weight) mixture of isopropanol : heptane containing $0.3 \mathrm{~g}$ of potassium laurate per $100 \mathrm{~g}$ of solution. It was added intermittently over a 170 hour pericd. The rate of addition was $50 \mathrm{~g} / \mathrm{hr}$ initially and $10 \mathrm{~g} / \mathrm{hr}$ for the final additions. A plot of the amount of potassium added (grams of potassium per 100 grams of iron) vs. hours-on-stream appears in Figures A-3 to A-6. The effect of this addition on catalyst performance was instantaneous and dramatic. The activity of the catalyst increased both for F-T and water gas shift (WGS) reactions. For instance, the CO conversion increased from $20 \%$ to $42 \%$ by the end of the potassium addition, at which time $3.6 \mathrm{~g}$ of potassium per $100 \mathrm{~g}$ of iron had been added. Over the same period of time the $\mathrm{CO}_{2}$ selectivity increased from $22 \%$ to $48 \%$. The effect of potassium addition was fully manifested at the $2.5 \mathrm{~g}$ level, addition to $3.6 \mathrm{~g}$ did not result in any further changes in conversion or to $\mathrm{CO}_{2}$ or light ends selectivity. The conversion was much higher in previous runs wherein $2.0-2.5 \mathrm{~g}$ of the potassium was present at the beginning either via the potassium impregnation/ calcination route or as potassium laurate added separately to the pre-run oil/oxide mix. Although the CO conversion was lower than expected for a catalyst with $2.5 \mathrm{~g}$ potassium $/ 100 \mathrm{~g}$ iron the water gas shift activity was as high as expected $\left(47 \% \mathrm{CO}_{2}\right.$ selectivity).

The potassium laurate addition affected the F-T and WGS conversions differently. After the first small addition of potassium $(0.5 \mathrm{~g} / 100 \mathrm{~g}$ of iron), there was a definite increase in the apparent WGS activity (higher $\mathrm{CO}_{2}$ selectivity), but no observable increase in the Fischer-Tropsch activity (Figure A-3). When 
the F-T activity (conversion) did begin to increase it did so very slowly at first. It is possible that the catalytic sites for the shift reaction are different than those for the Fischer-Tropsch reaction. The F-T site might require more than one potassium and, therefore, not being very prevalent until the bulk potassium level reaches a fairly high level, whereas the WGS sites might require only one potassium. Sites of the latter type would be formed as soon as potassium reaches the catalyst.

Since the conversion was still low after all of the potassium laurate additions, the temperature was increased near the end of the run to obtain selectivities at high conversion. At $290^{\circ} \mathrm{C}$ the conversions were similar to those in the earlier Run 37 (Table 1), but the methane + ethane selectivity was much lower, 3.1 vs $4.8 \mathrm{~mol} \%$. Run 37 was the best run of a previous set in which the effect of potassium level was determined (potassium from potassium carbonate impregnation/calcination). Higher potassium catalysts in this set exhibited the low methane + ethane selectivity above but were less active, whereas lower potassium ones exhibited higher methane + ethane selectivities although having equivalent activity to the Run 37 catalyst No. 6616-100.

\section{Run 49}

In this run an iron-copper oxide (Catalyst 6827-17) was used which had been impregnated with a low level of potassium via the potassium carbonate impregnation/calcination method. The amounts of ironcopper oxide and $C_{30}$ oil and the activation procedure were the same as in Run 46 . The plots of conversions and selectivities vs. hours-on-stream are in Figures A-11 to A-21. As expected, the line-out conversion was higher than that of the no-potassium catalyst 6616-189 of Run 46. After line-out the potassium laurate solution was added intermittently at the rate of $50 \mathrm{~g} / \mathrm{hr}$, again resulting in an instantaneous change in the catalyst performance. The conversions increased, for instance the $\mathrm{CO}$ conversion increased from $37 \%$ to $72 \%$, and the light product selectivities decreased, for instance, the methane selectivity decreased from 6.8 to $2.7 \mathrm{~mol} \%$.

During both Runs 46 and 49 potassium laurate was added past the point where further activity increases were noted. The ultimate conversion in Run 49 was greater than Run 46. Thus incorporation of a small amount of potassium by potassium carbonate impregnation made the catalyst more responsive to the potassium laurate addition. Summary data from Run 49 are compared to similar data from Runs 37,42 , 43, and Run 46 in Table 1. Key data in this table are those from Fe:K wt. ratio $=2.1$. During an earlier study of the effect of potassium on performance (potassium carbonate impregnation) it was found that this ratio provided optimum performance. Lesser amounts of potassium resulted in higher methane selectivities and greater amounts of potassium resulted in less conversion. The data from Run 49 are superior in two regards. First of all at the 100:2.1 ratio of $\mathrm{Fe}: \mathrm{K}$ a high conversion was achieved with, however, the lowest methane + ethane selectivity of any of the previous runs with catalysts containing $\mathrm{Fe}$ and $\mathrm{K}$ in 100:2.1 ratio. Secondly, when more potassium laurate was added (ratio $=100: 3.0$ ) the conversion did not decrease, but the light end selectivities did with the result that the methane + ethane selectivity was the lowest ever obtained during this contract at high conversion (and target temperature).

\section{Runs 47 and 52}

These two runs used separate fresh lots of a catalyst (6616-160) prepared in the same way as the Run 37 catalyst. The activation procedure of Runs 46 and 49 was used. Run 47 was a reference run which is compared to Run 37 in Table 2. The main objective of Run 52 was determination if addition of the potassium laurate solution during a run with an optimal potassium-level catalyst could lead to performance 
improvements. Thus Run 52 was the same as Run 47 initially, then potassium laurate solution was added. Run 52 is also summarized in Table 2. Late in both Runs 47 and 52 condition changes were made to achieve secondary objectives. Conversions and selectivities vs. hours-on-stream from Runs 47 and 52 are summarized in Figures A-22 to A-37.

The potassium present at start-up in the Runs 37,47 and 52 catalysts resulted from potassium carbonate impregnation/calcination. Catalyst 6616-100 (Run 37) was the best resulting from a previous study of the effect of the level of such potassium on catalyst performance. It was active yet produced low levels of methane and ethane. Although catalysts 6616-100 (Run 37) and 6616-160 (Run 47) were prepared identically they had slightly different properties and performance characteristics. However, the performance differences were probably no more than to be expected on a run-to-run basis. For instance, when catalyst 6616-160 was used again in Run 52 the performance prior to potassium laurate addition was closer to that of catalyst $6616-100$ (Run 37 ).

Methanol ( $50 \mathrm{~g} / \mathrm{hr}$ ) was added continually during Run 47 from 175 to 195 hours-on-stream. This resulted in some depression in the conversion during the addition but after withdrawal of the methanol the conversion came back to a level higher than before the addition began. However, catalyst deactivation from this level resumed quickly.

Intermittent addition of the potassium laurate solution was started at the usual rate at 145 hours on stream during Run 52. No major changes in catalyst performance were noted. A small loss in conversion resulted from the first potassium laurate addition. In previous work with potassium carbonate impregnated catalysts conversion losses were also noted when the amount of potassium carbonate exceeded $2.1 \mathrm{~g} \mathrm{~K} / 100 \mathrm{~g} \mathrm{Fe}$. The subsequent potassium laurate additions up to $3.4 \mathrm{~g} \mathrm{~K} / 100 \mathrm{~g} \mathrm{Fe}$ produced no further decreases in the conversion.

Methane selectivity decreased throughout the first 220 hours of Run 52, but at line-out was still $4.3 \%$. There was no change in the rate of decrease in the methane selectivity during the first potassium laurate addition. The second and third potassium additions which occurred after line-out produced no change in the methane selectivity.

The ethane and ethylene selectivities also reached line-out over the first 220 hours-on-stream. Both these selectivities were slightly affected by the first potassium laurate addition, and in the case of ethylene by the third potassium laurate addition as well.

At 450 hours-on-stream the $\mathrm{CO}$ conversion was a respectable $74 \%$ but the sum of methane + ethane selectivities was high, $5.6 \%$. It thus appears that the addition of potassium laurate solution to a functioning catalyst produces the best results when the original catalyst contains some potassium, but not the full amount (approximately $2.1 \mathrm{~g} \mathrm{~K} / 100 \mathrm{~g} \mathrm{Fe}$ ).

Two additional experiments were done near the end of the Run 52. In the first the plant pressure was increased from 290 to $450 \mathrm{psig}$. This caused an immediate increase in the conversions, for instance, the CO conversion increased from 74 to $86 \%$ but then began to decrease. The pressure increase also caused an increase in the methane selectivity of several tenths of a percent. There were small changes in the other selectivities as well. The second of the additional experiments was re-introduction of a second (liquid) feed. However, this time the feed was hexane at the rate of $50 \mathrm{~g} / \mathrm{hr}$ (530 to 580 hours on stream). This addition produced an immediate affect on the conversions and selectivities. The CO 
conversion dropped, for instance, from $83 \%$ to $74 \%$. The methane selectivity decreased from 4.5 to $4.2 \%$, the ethane selectivity decreased from 1.6 to $1.3 \mathrm{~mol} \%$, but the ethylene selectivity, which still seemed to be reacting to the pressure increase, did not seem to be affected additionally by the hexane addition. The $\mathrm{C}_{3}$ and $\mathrm{C}_{4}$ (olefins and paraffins) were more noticeably affected by the hexane addition than the $\mathrm{C}_{1}$ and $\mathrm{C}_{2}$ 's. This indicates a more steeply inflected $\alpha_{1}$ (lower $\alpha_{1}$ ). The net result would be less product mass in the light products, but more product mass in the high molecular weight products. A possible explanation is that the hexane dilutes (decreases residence time) the light molecules in the autoclave (molecules which exist predominantly in the gas phase in the reactor along with hexane). This means the reactant gases do not have an opportunity to react as extensively (lower conversions) and the light product olefins do not have as great a chance to react back with the catalyst to initiate higher molecular weight chains. However, the molecules that do grow large enough to exist predominantly in the liquid phase of the reactor still can react back to initiate new chains and thus grow to even higher molecular weights.

\section{Conclusions}

Figures A-38 to A-40 are plots of, respectively, methane, ethane and ethylene selectivities vs. conversion. Line-out data from six runs are summarized in these plots. Some of the data from Runs 43 and 46 were obtained at temperatures other than $265^{\circ} \mathrm{C}$, all other data were obtained at $265^{\circ} \mathrm{C}$. For runs with catalysts containing a high initial level of potassium (either from potassium addition before startup, Run 43 , or from potassium carbonate impregnation/calcination, Runs 37,47 and 52 , the methane and ethane selectivities increased with conversion. However, data from Runs 46 and 49 fell below the line defined by data from the other runs. At any conversion the methane selectivity was lower during Runs 46 and 49 than in the other runs. In the case of ethane selectivity only the $290^{\circ} \mathrm{C}$ data from Run 26 fell below the line. The addition of potassium laurate during a run with a no or low potassium catalyst appears, therefore, to have produced a different, lower methane/ethane catalyst than the others prepared as part of this contract. A similar potassium laurate addition during a run with a high potassium catalyst did not produce such a catalyst.

Thus a solution of potassium laurate can be used to modify the properties of an iron-based FischerTropsch catalyst during a run. This means the benefit of using potassium laurate is not just as a way to replace potassium carbonate impregnation for controlling the start-of-run potassium level. Adding a solution of potassium laurate during a run has allowed preparation of catalysts which exhibit the lowest selectivities to methane and ethane at high conversion of any catalysts evaluated to date during this contract.

It is know'n that the initial iron-copper oxide catalyst changes drastically during the early stages of a run. The initial oxides are reduced to a mixture of oxygenated and carbided metals. This reduction occurs in stages with various mixtures being present at any time. Typically, the catalyst takes fifty to one hundred and fifty hours to reach an equilibrium composition. It is possible that different results will be obtained depending upon when the potassium laurate solution is added during the time the original ironcopper oxide is being reduced.

\section{Plans for the Next Quarter}

Evaluate other potassium-containing molecules as vehicles to carry potassium to the iron-based FischerTropsch catalyst during a run. 


\section{TABLE 1}

PERFORMANCE SUMMARY: TWO POTASSIUM ADDITION METHODS

(LINED OUT CATALYSTS)

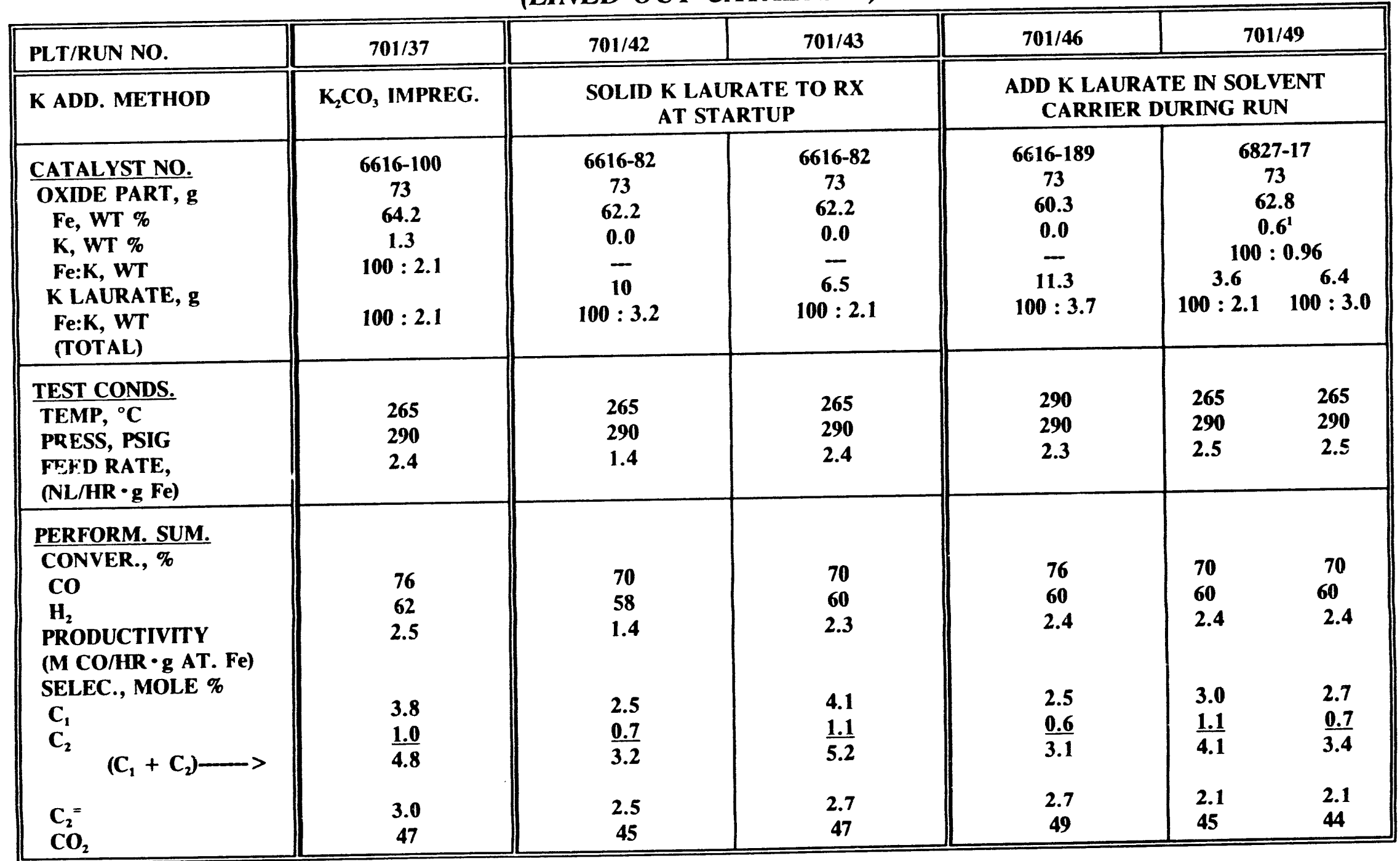

1. FROM $\mathrm{K}_{2} \mathrm{O}_{3}$ IMPREGNATION 
TABLE 2

PERFORMANCE SUMMARY: TWO POTASSIUM ADDITION METHODS

(LINED OUT CATALYSTS)

\begin{tabular}{|c|c|c|c|c|c|c|}
\hline PLT/RUN NO. & $701 / 37$ & $701 / 47$ & 701/52 & $701 / 46$ & \multicolumn{2}{|c|}{$701 / 49$} \\
\hline $\begin{array}{l}\text { CATALYST NO. } \\
\text { OXIDE PART, g } \\
\text { Fe, WT \% } \\
\text { K, WT \% } \\
\text { Fe:K, WT } \\
\text { K LAURATE }{ }^{2}, \mathrm{~g} \\
\text { Fe:K, WT } \\
\text { (TOTAL) } \\
\end{array}$ & $\begin{array}{c}6616-100 \\
73 \\
64.2 \\
1.3^{1} \\
100: 2.1 \\
100: 2.1\end{array}$ & $\begin{array}{c}6616-160 \\
73 \\
57.0 \\
1.3^{1} \\
100: 2.1 \\
100: 2.1\end{array}$ & $\begin{array}{c}6616-160 \\
73 \\
57.0 \\
1.3^{1} \\
100: 2.1 \\
3.3 \\
100: 3.4\end{array}$ & $\begin{array}{c}6616-187 \\
73 \\
60.3 \\
0.0 \\
- \\
11.3 \\
100: 3.7\end{array}$ & $\begin{array}{r}68 \\
\\
100 \\
3.6 \\
100: 2.1\end{array}$ & $\begin{array}{l}-17 \\
8 \\
5^{1} \\
0.96 \\
6.4 \\
100: 3.0\end{array}$ \\
\hline $\begin{array}{l}\text { TEST CONDS. } \\
\text { TEMP, }{ }^{\circ} \mathrm{C} \\
\text { PRESS, PSIG } \\
\text { FEED RATE, } \\
(\mathrm{NL} / \mathrm{HR} \cdot \mathrm{g} \text { Fe) } \\
\end{array}$ & & $\begin{array}{l}265 \\
290 \\
2.4\end{array}$ & & $\begin{array}{l}290 \\
290 \\
2.3\end{array}$ & $\begin{array}{l}265 \\
290 \\
2.5\end{array}$ & $\begin{array}{c}265 \\
290 \\
2.5\end{array}$ \\
\hline $\begin{array}{l}\text { PERFORM. SUM. } \\
\text { CONVER., \% } \\
\text { CO } \\
\mathrm{H}_{2} \\
\text { PRODUCTIVITY } \\
\text { (M CO/HR } \cdot \mathrm{g} \text { AT. Fe) } \\
\text { SELEC., MOLE \% } \\
\mathrm{C}_{1} \\
\mathrm{C}_{2} \\
\quad\left(\mathrm{C}_{1}+\mathrm{C}_{2}\right) \longrightarrow \\
\mathrm{C}_{2}= \\
\mathrm{CO}_{2}\end{array}$ & $\begin{array}{l}3.8 \\
1.0 \\
4.8 \\
3.0 \\
47\end{array}$ & \begin{tabular}{r|}
3.2 \\
$\frac{1.0}{4.2}$ \\
\\
2.7 \\
46
\end{tabular} & $\begin{array}{c}75 \\
62 \\
2.5 \\
\\
4.3 \\
\underline{1.3} \\
5.6 \\
\\
3.4 \\
50 \\
\end{array}$ & $\begin{array}{l}2.5 \\
0.6 \\
3.1 \\
\\
2.7 \\
49\end{array}$ & $\begin{array}{l}3.0 \\
1.1 \\
4.1 \\
2.1 \\
45\end{array}$ & $\begin{array}{l}70 \\
60 \\
2.4 \\
\\
2.7 \\
0.7 \\
3.4 \\
\\
2.1 \\
44 \\
\end{array}$ \\
\hline
\end{tabular}

1. FROM $\mathrm{K}_{2} \mathrm{O}_{3}$ IMPREGNATION

2. ADDED IN SOLUTION DURING THE RUN 
POTASSIUM FREE CATALYST/NNTERMTTIENT K-LAURATE ADDMON (K-LAURATE $0.03 \mathrm{~g} / 10 \mathrm{~g} 50: 50(\mathrm{~W})$ HEPTANE : ISOPROPANOL)

PLT $700 \mathrm{~B}$ RUN $46 \mathrm{H}_{2}: \mathrm{CO}(\mathrm{M})$ food=0.7, $1100 \mathrm{rpm}$ ( $\sqrt{27-\rightarrow 2 / \pi / 92}$ )

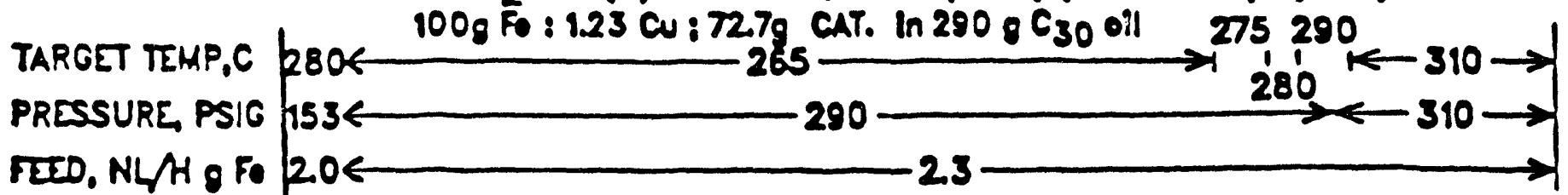
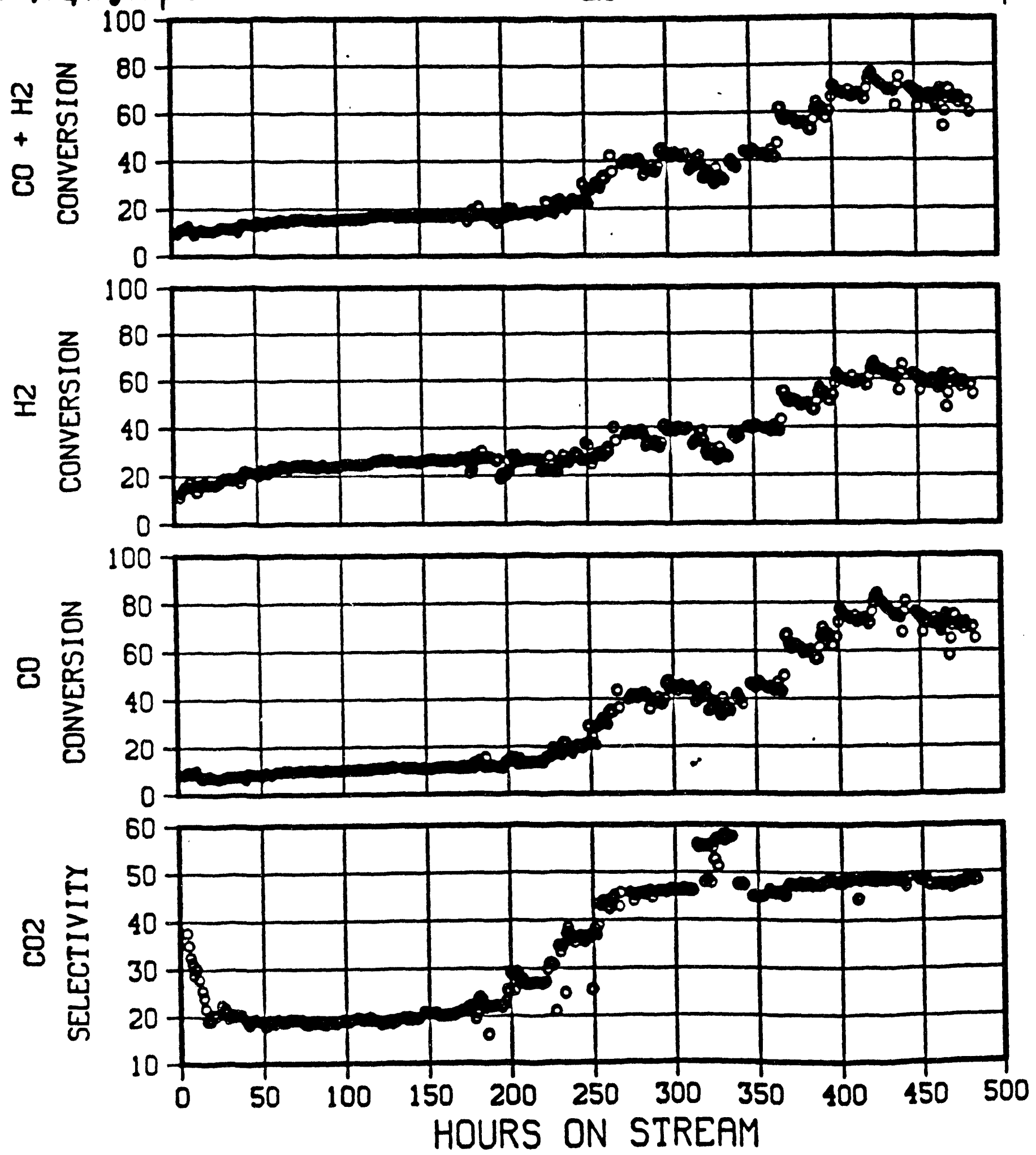
POTASSIUM FREE CATALYST/INTERMITTENT K-LAURATE ADDMON (K-LAURATE $0.03 \mathrm{~g} / 10 \mathrm{~g} 50: 50(\mathrm{~W})$ HEPTANE : ISOPROPANOL)

PLT 700B RUN $46 \mathrm{H}_{2}: \mathrm{CO}(\mathrm{M})$ food=0.7, $1100 \mathrm{rpm}(\sqrt{27}-->2 / 7 / 92)$
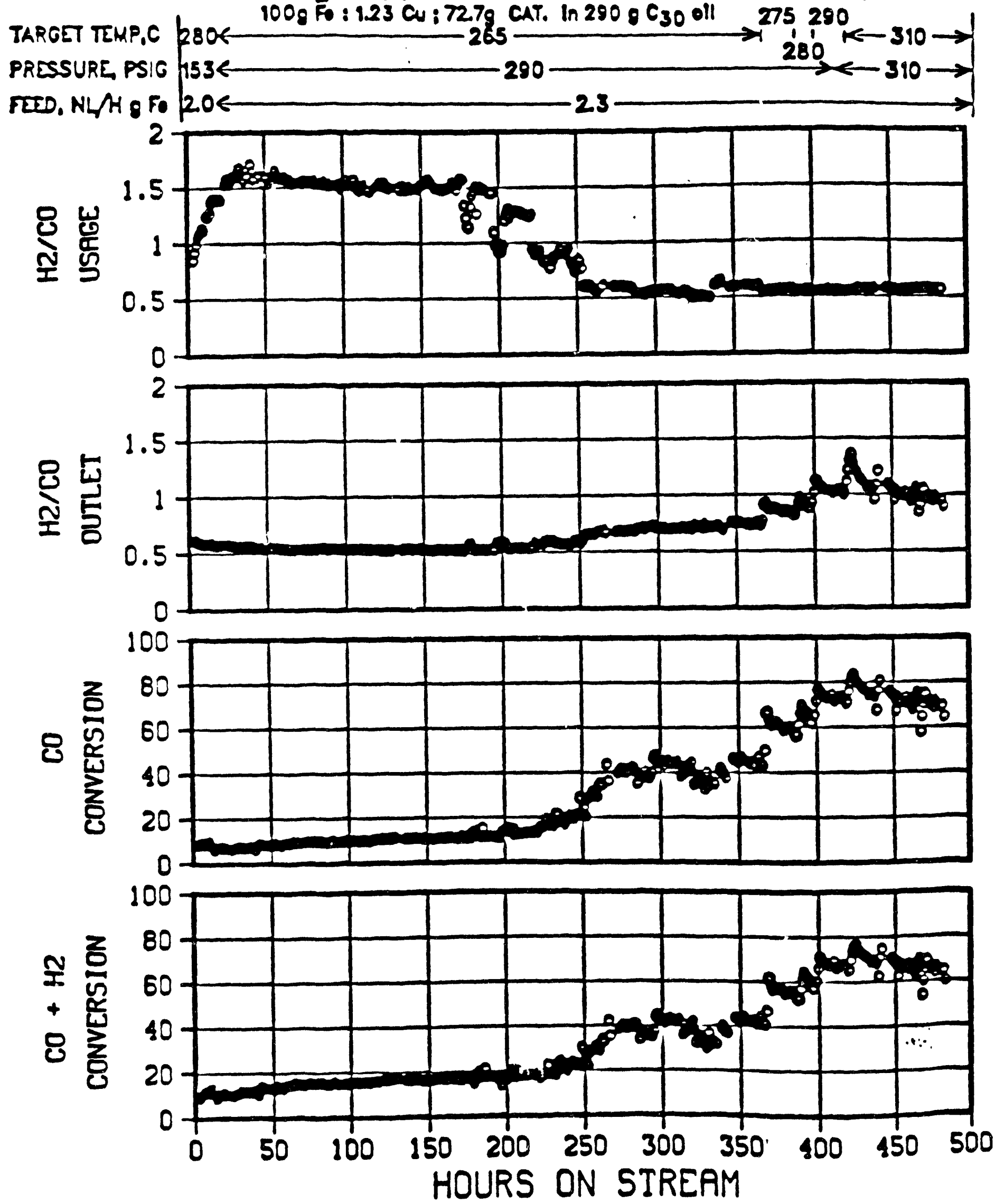
WUJYIS NO SUחOH

OOS OSR OOH OSE OOE OSZ OOZ OSI OOL OS 0
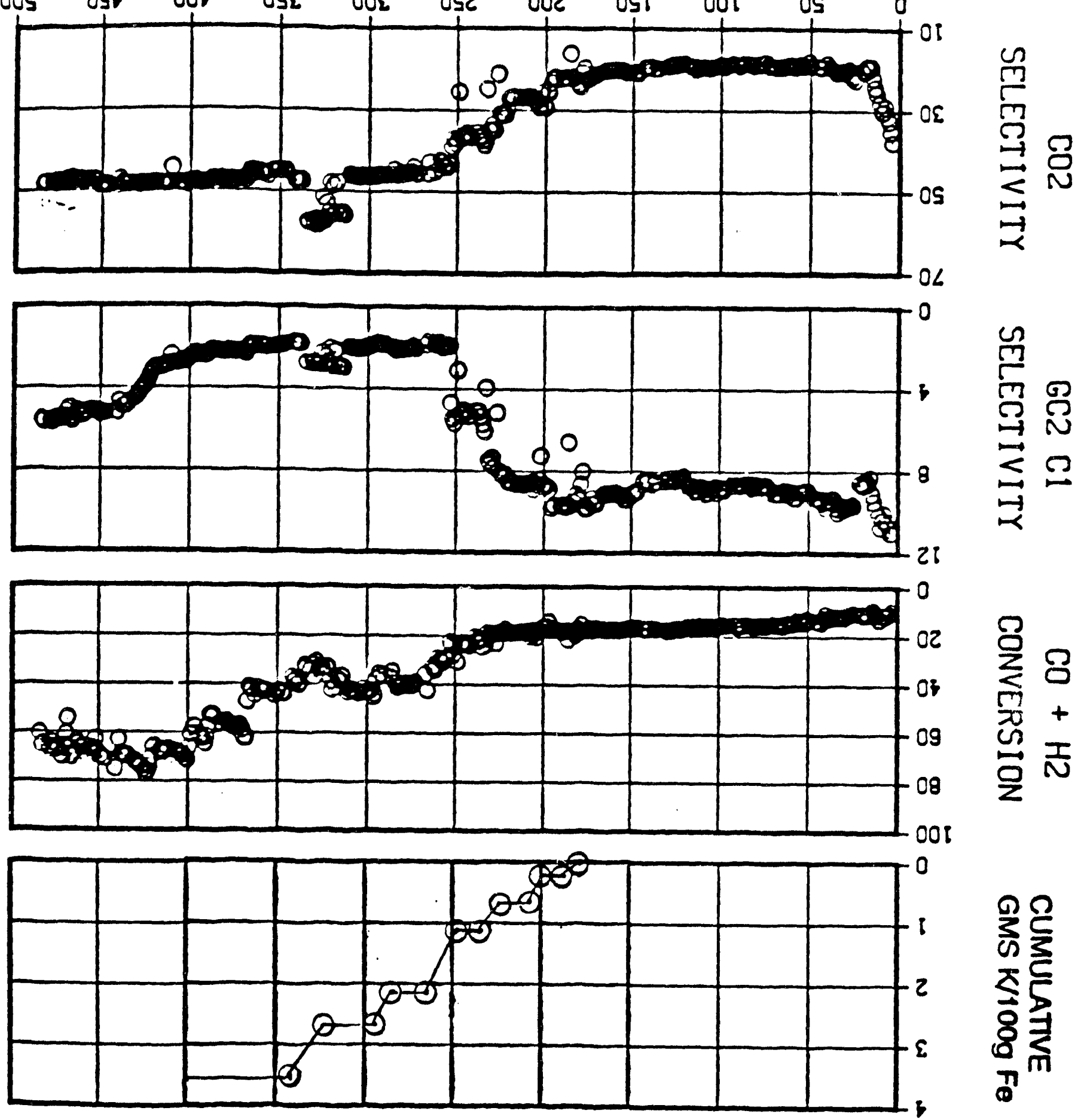

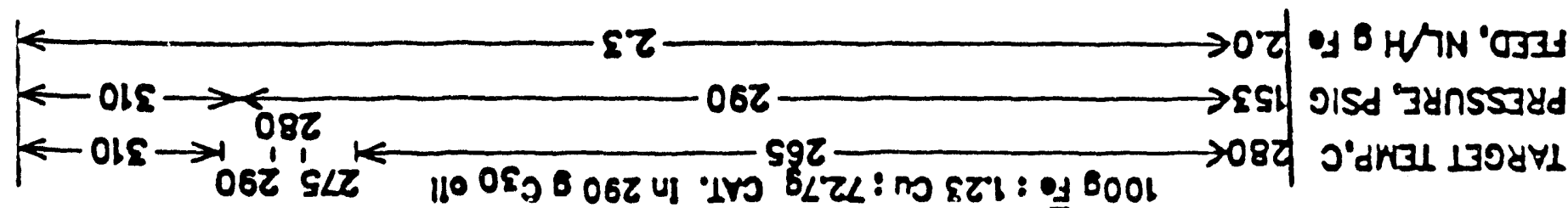

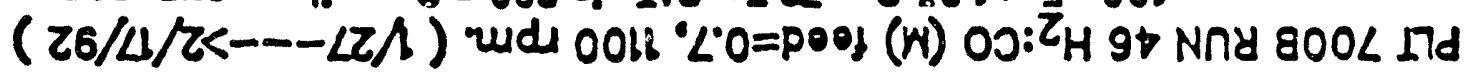

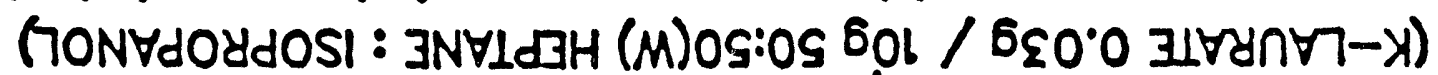
Now 
POTASSIUM FREE CATALYST/INTERMITIENT K-LAURATE ADDITON (K-LAURATE $0.03 \mathrm{~g} / 10 \mathrm{~g} 50: 50(\mathrm{~W})$ HEPTANE : ISOPROPANOL)

PLT 700B RUN $46 \mathrm{H}_{2}: \mathrm{CO}(\mathrm{M})$ food=0.7, $1100 \mathrm{rpm}$ ( $\left.\sqrt{27}-\rightarrow-72 / \pi / 92\right)$
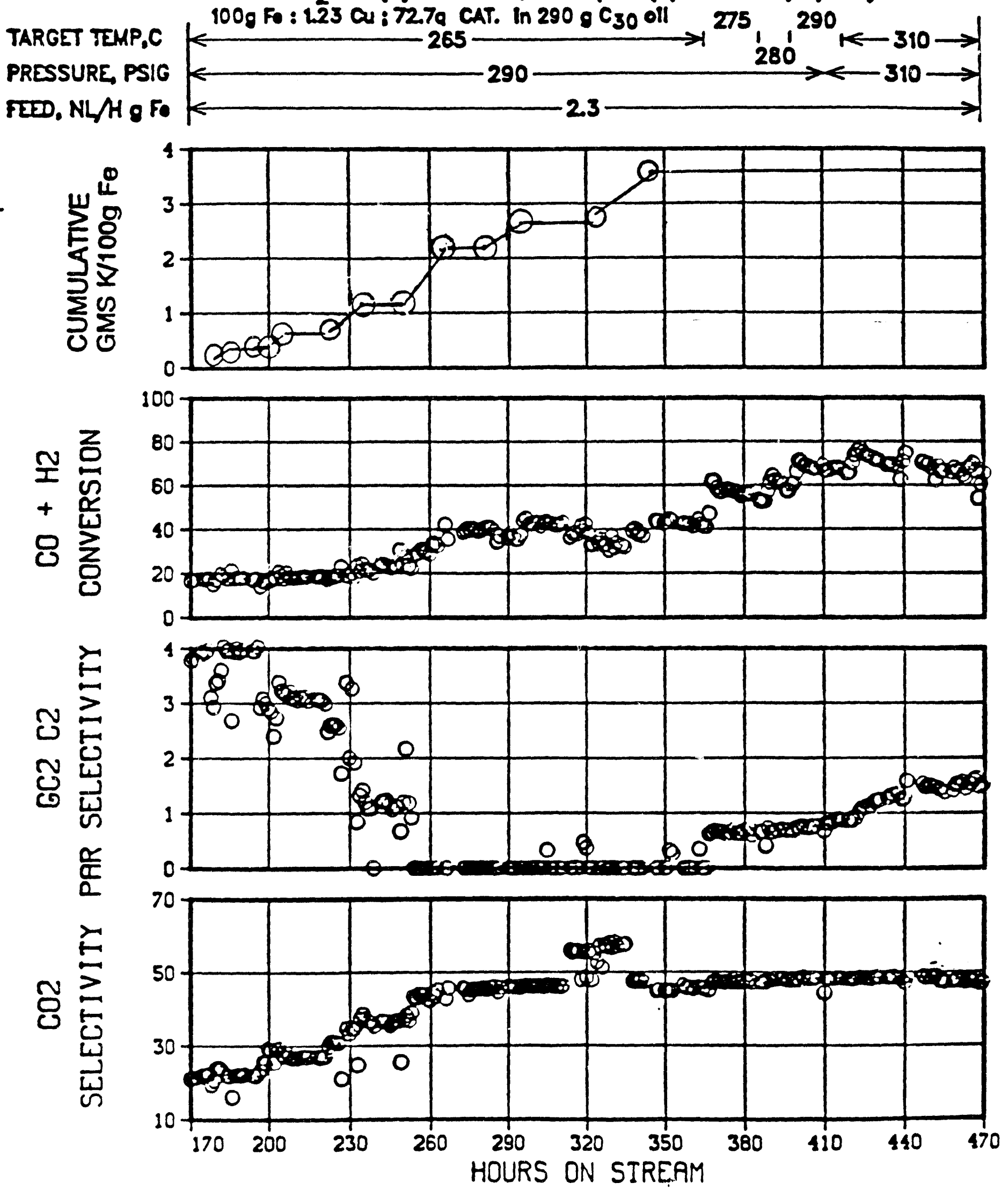
FIGURE A-5

POTASSIUM FREE CATALYST/INTERMITTENT K-LAURATE ADDITON (K-LAURATE $0.03 \mathrm{~g} / 10 \mathrm{~g} 50: 50$ (W) HEPTANE : ISOPROPANOL)

PLT 700B RUN $46 \mathrm{H}_{2}: \mathrm{CO}$ (M) food=0.7, $1100 \mathrm{rpm}$ ( $\sqrt{27} \longrightarrow \rightarrow 2 / 7 / / 92$ ).
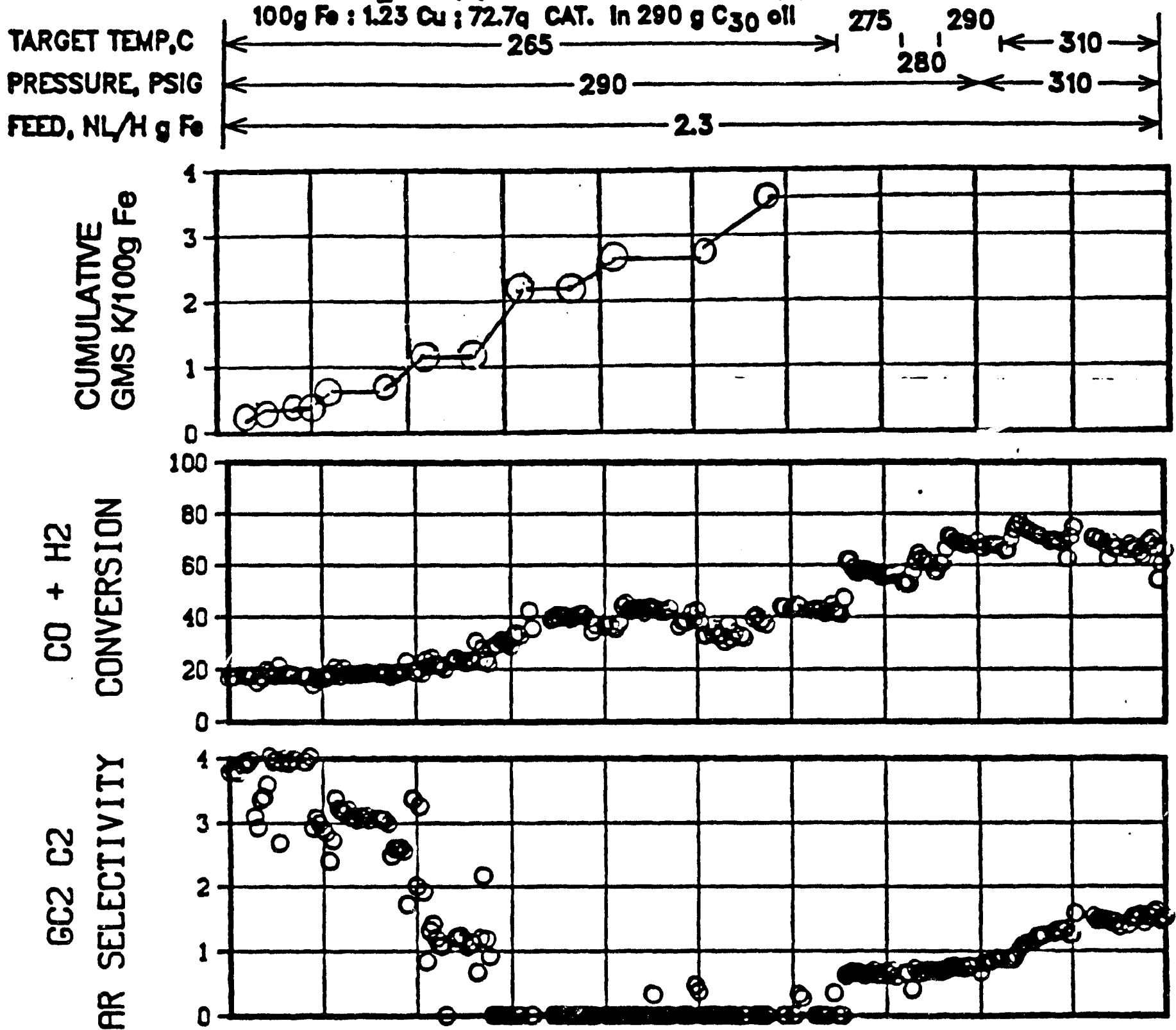

ט

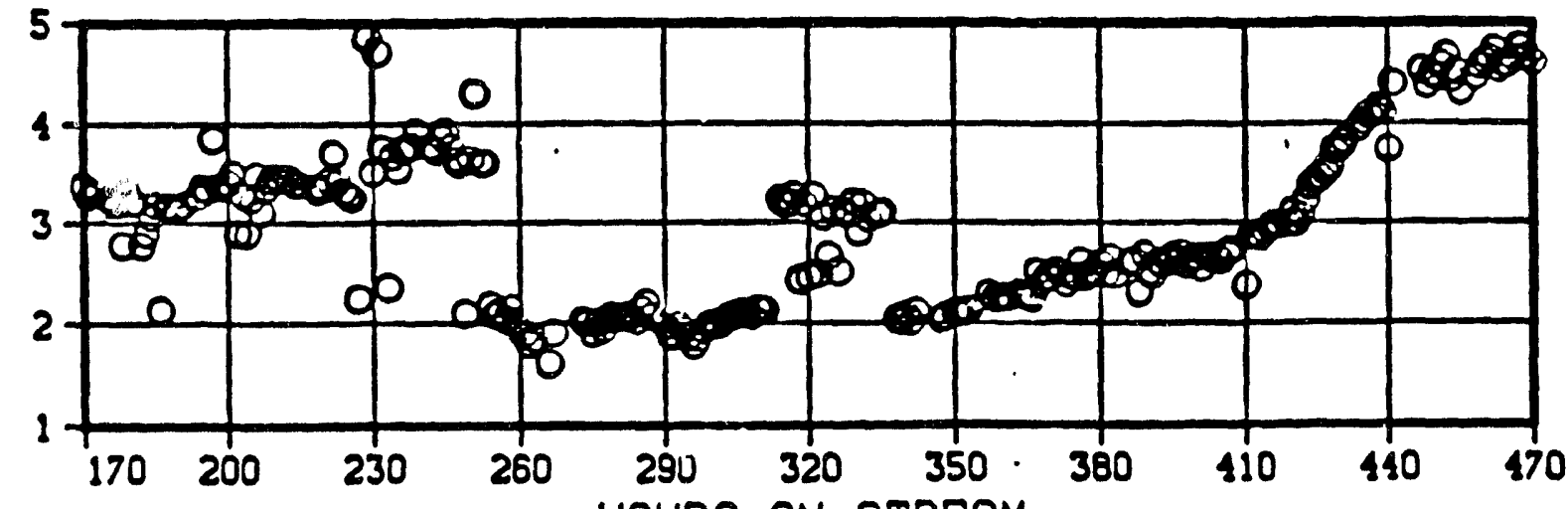

HOURS ON STREAM 


\section{FIGURE A-6}

POTASSIUM FREE CATALYST/INTERMITIENT K-LAURATE ADDITON (K-LAURATE $0.03 \mathrm{~g} / 10 \mathrm{~g} 50: 50(\mathrm{~W})$ HEPTANE : ISOPROPANOL)

PLT 700B RUN $46 \mathrm{H}_{2}: \mathrm{CO}(\mathrm{M})$ food $=0.7,1100 \mathrm{rpm}$ ( $\sqrt{27} \longrightarrow \rightarrow 2 / 17 / 92$ )

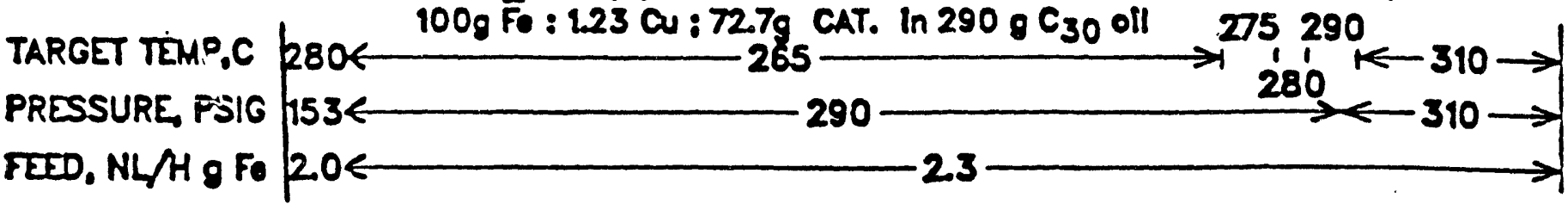
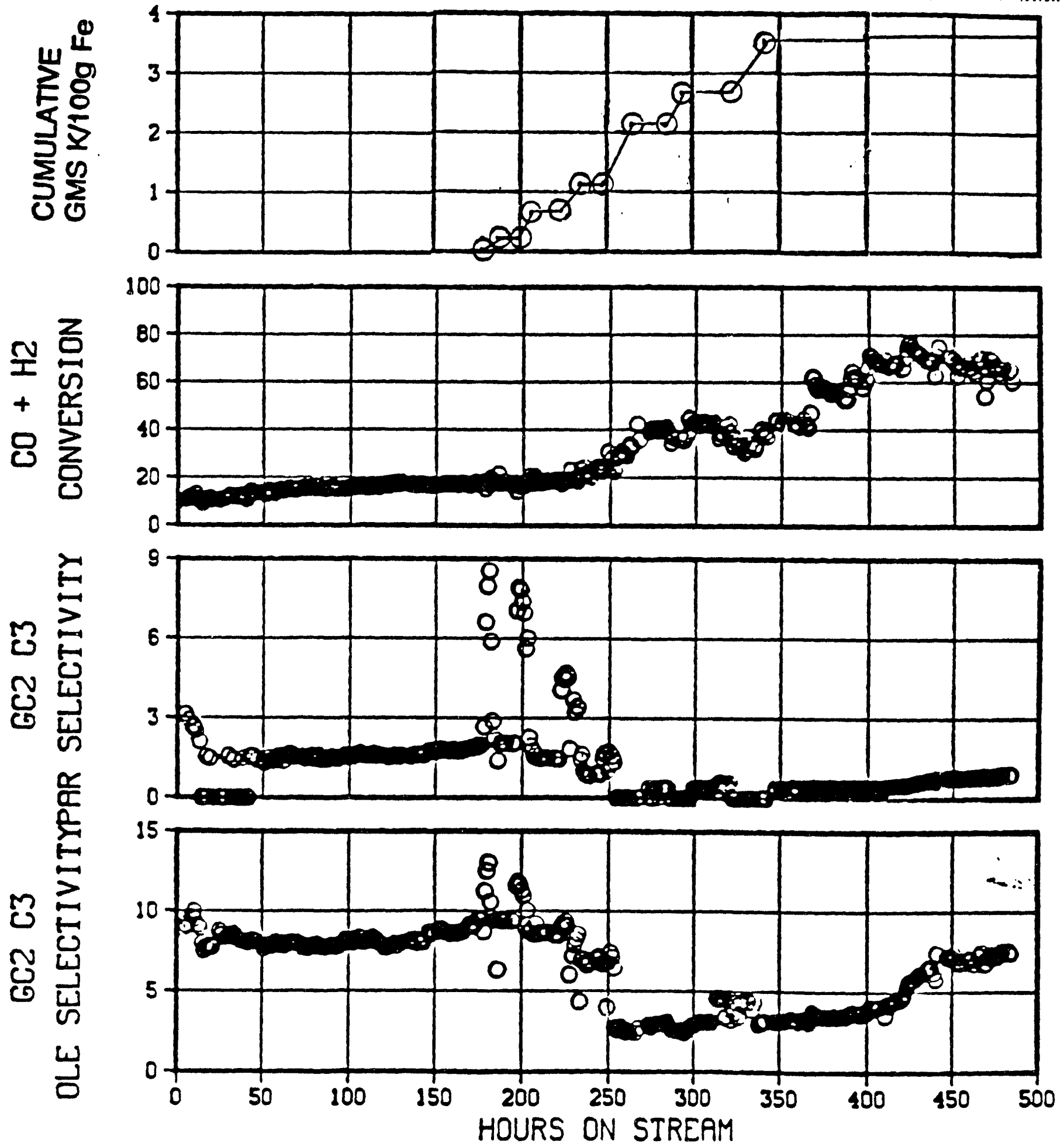
POTASSIUM FREE CATALYST/INTERMITIENT K-LAURATE ADDMON ( $K$-LAURATE $0.03 \mathrm{~g} / 10 \mathrm{~g} 50: 50$ (W) HEPTANE : ISOPROPANOL)

- PLT 7008 RUN $46 \mathrm{H}_{2}: \mathrm{CO}(M)$ food=0.7, $1100 \mathrm{rpm}(\sqrt{27-}-2 / \pi / 92)$

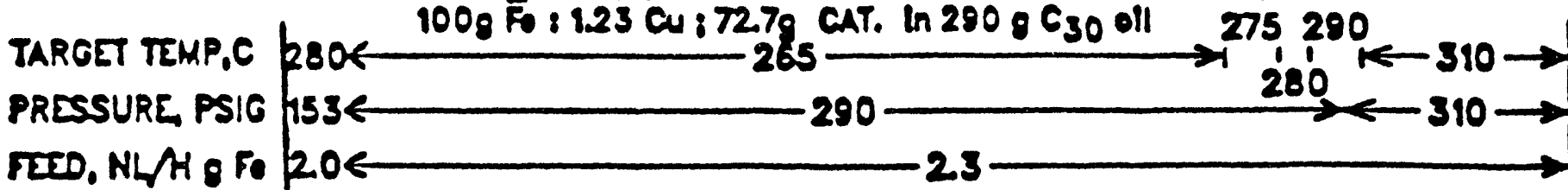
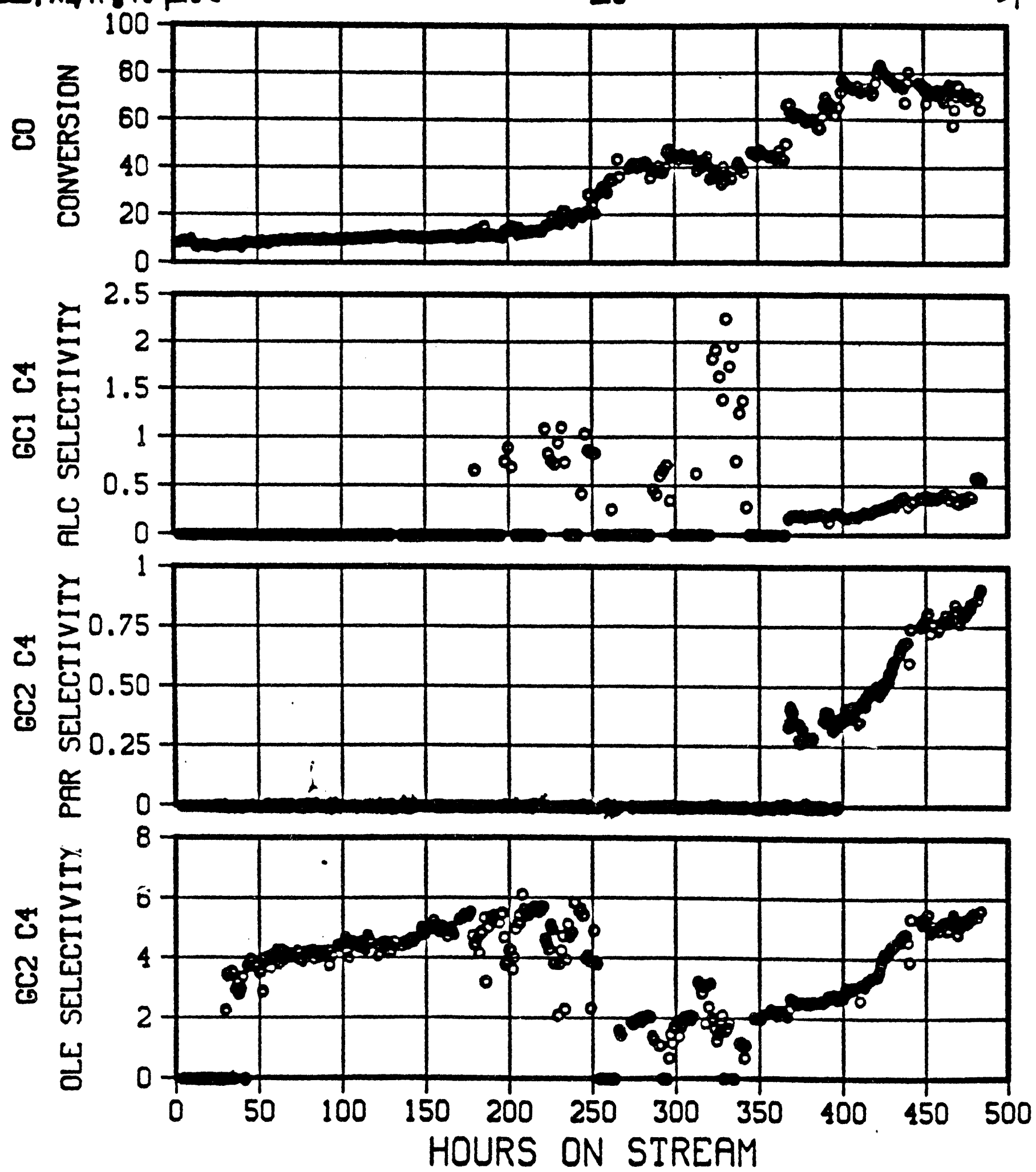
-POTASSIUM FREE CATALYST/ANTERMITTENT K-LAURATE ADDTION (K-LAURATE $0.03 \mathrm{~g} / 10 \mathrm{~g}$ 50:50(W) HEPTANE : ISOPROPANOL)

PL $700 \mathrm{~B}$ RUN $46 \mathrm{H}_{2}: \mathrm{CO}(\mathrm{M})$ fooc $=0.7,1100 \mathrm{rpm}$ ( $/ 27-->2 / \pi / 92$ )

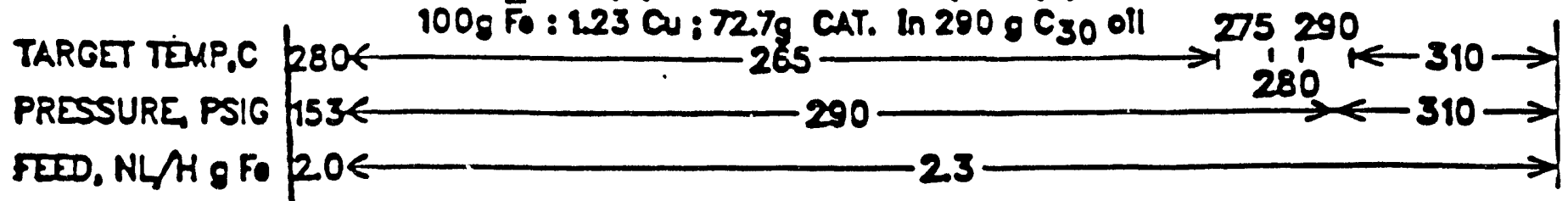
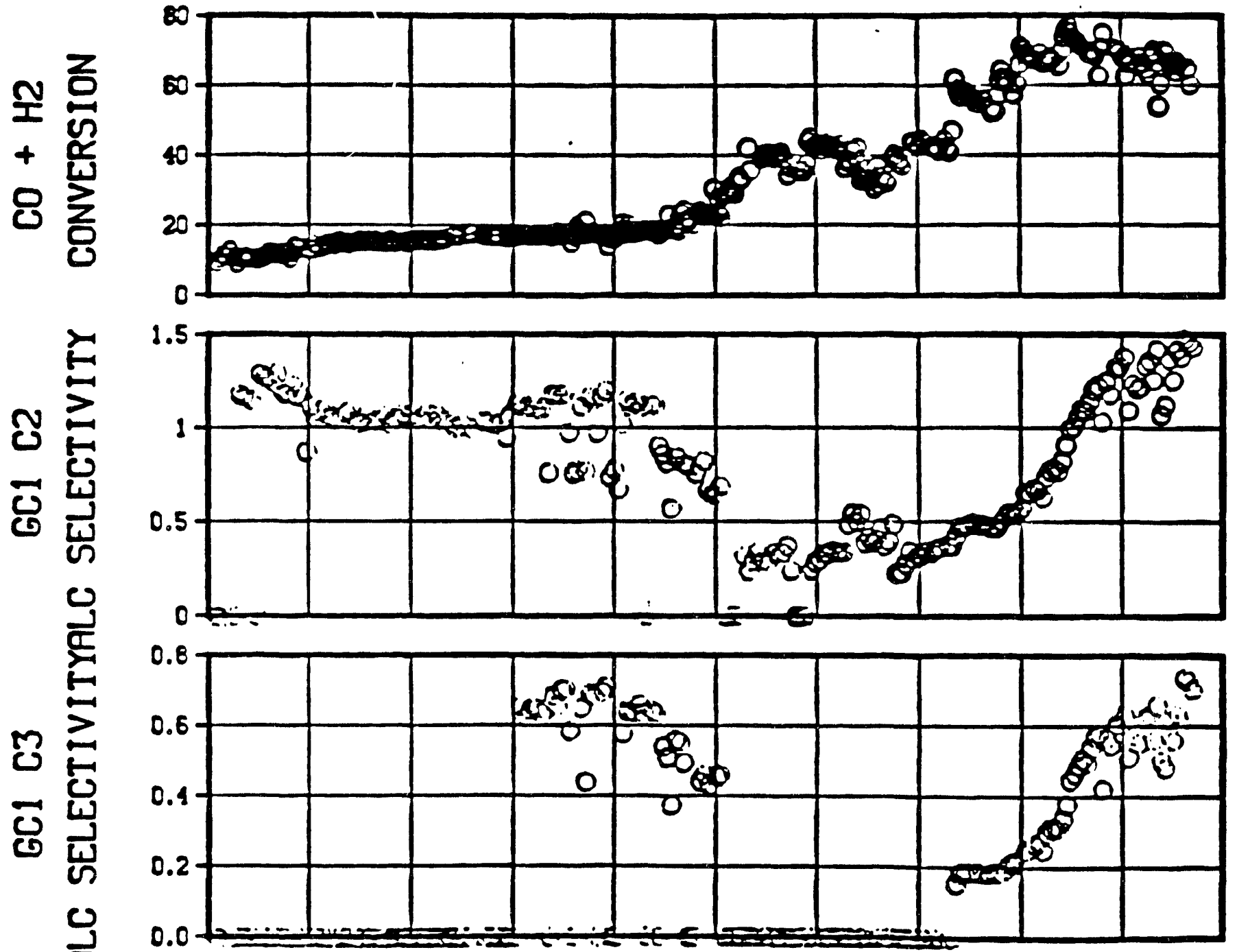

2

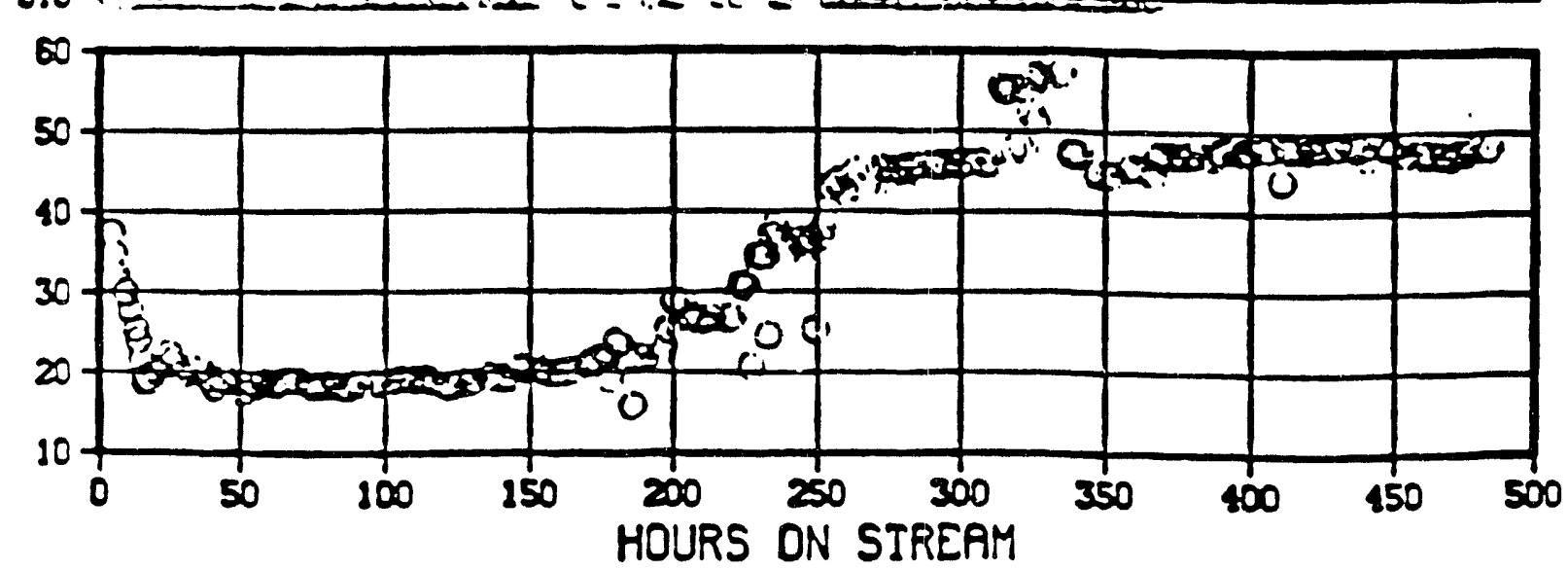




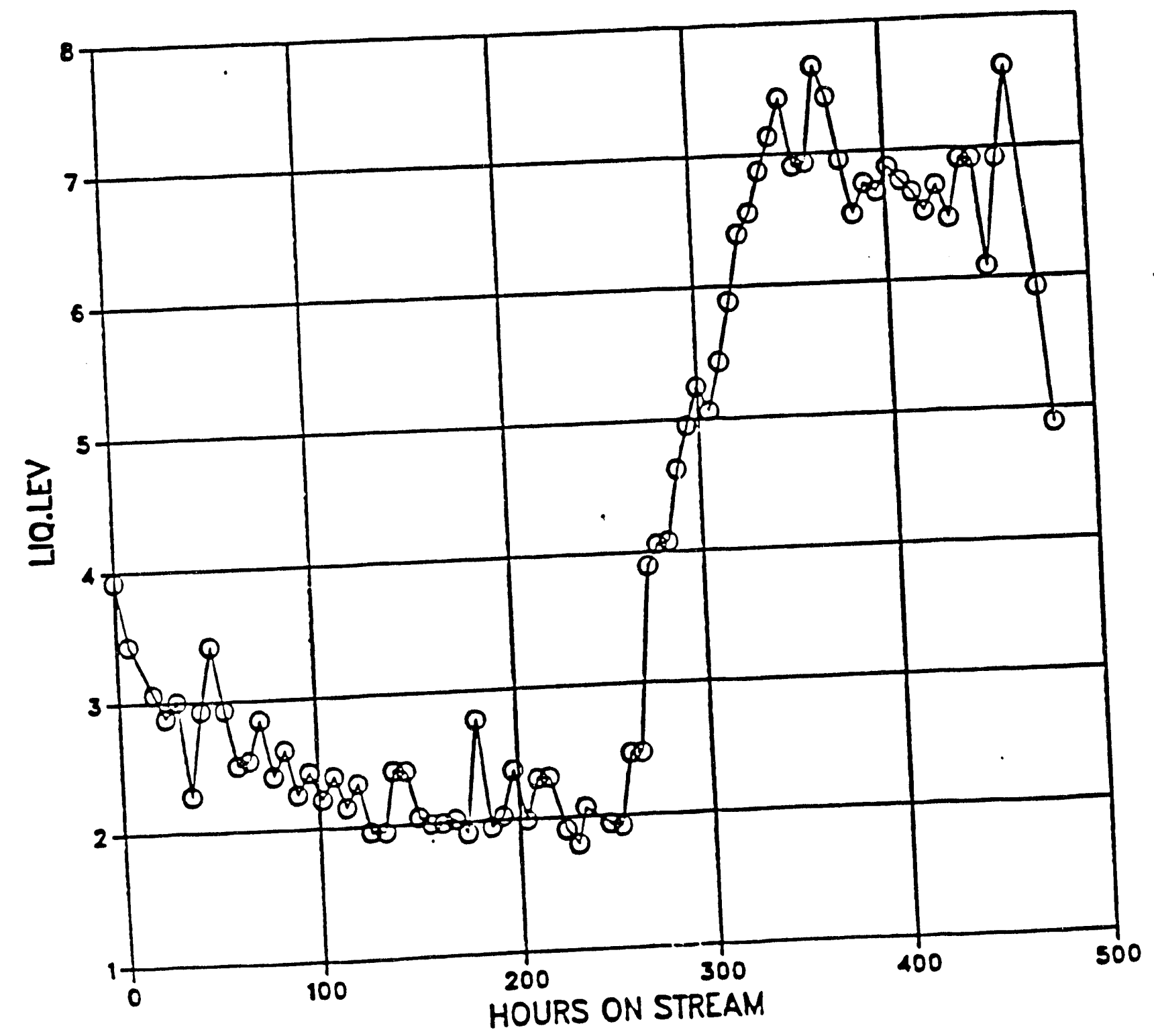


FIGURE A-10

\section{Effect of K Level on Cat Performance}

Run 46

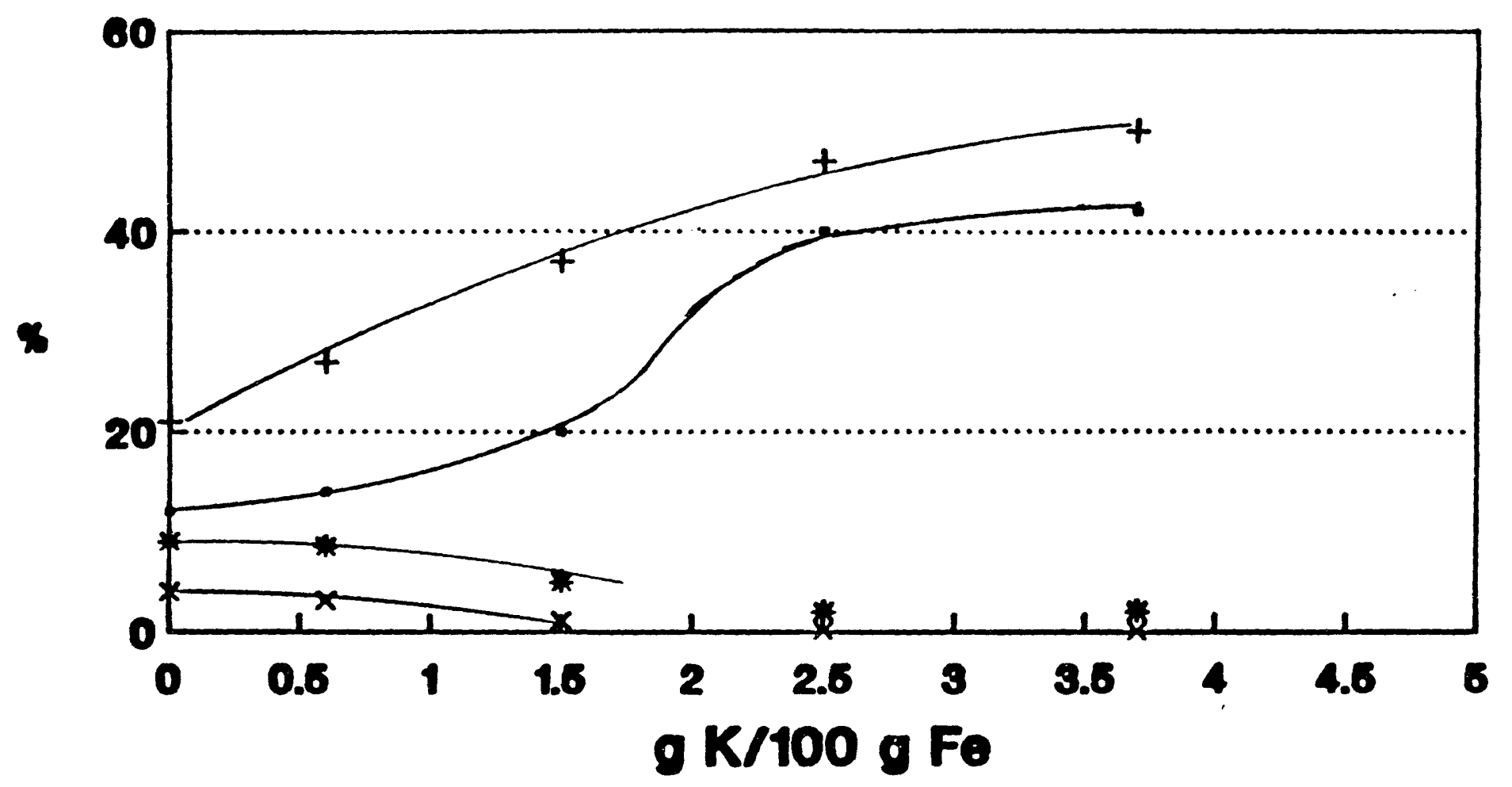

- co Conv

$+\quad C 0280100$

* Mothans soleo

$\times$ Ethane soloo 


\section{PLT 700B RUN 49 INTERMITIENT CO-FEED POTASSIUM \\ $72.7 \mathrm{~g} 6827-77$ in $290 \mathrm{~g} \mathrm{C}_{30}$ oil \\ $0.0405 w \% \mathrm{~K}$-LAURATE in 50/50 IPA/HEPTANE}
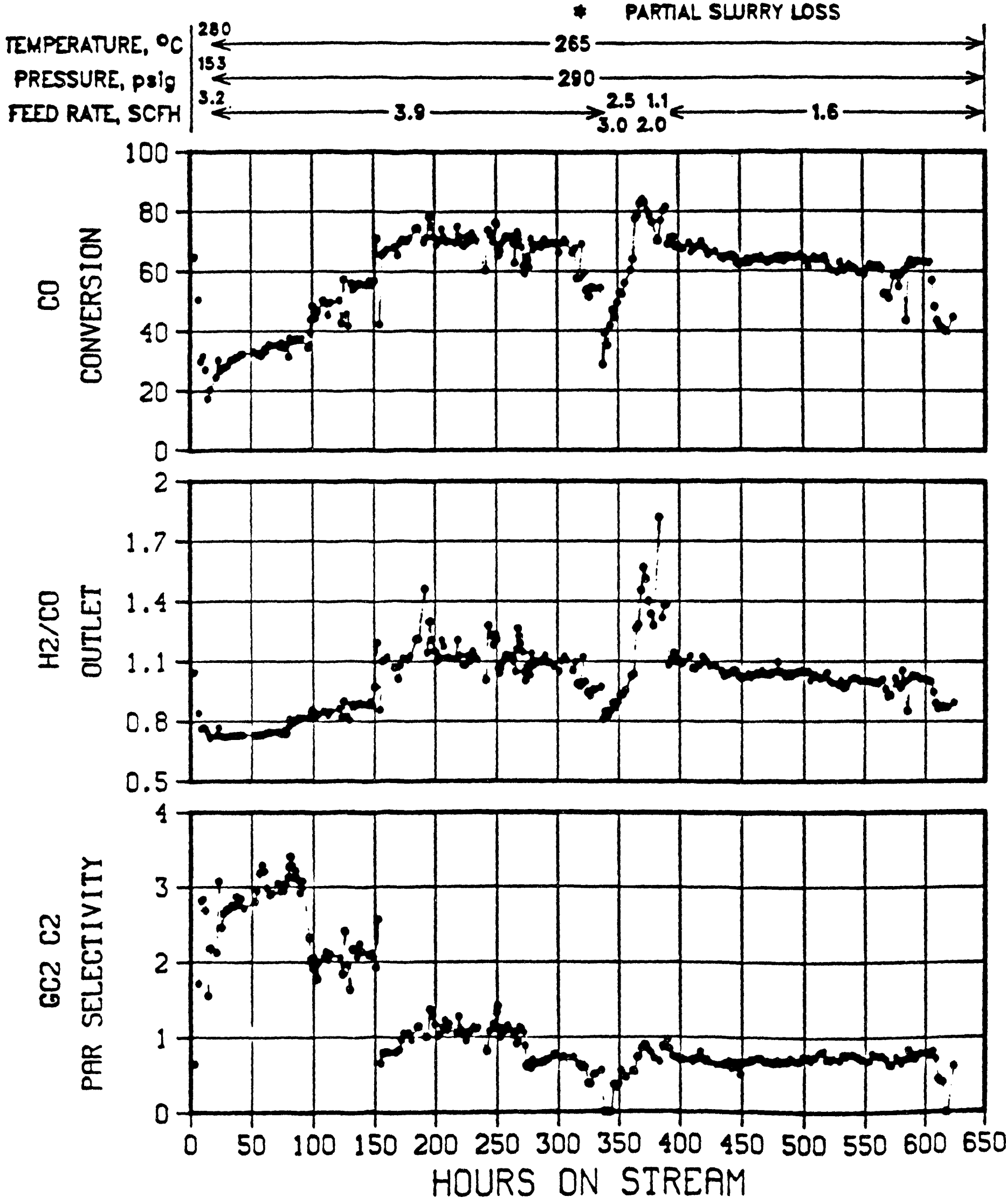


\section{FIGURE A-13}

PLT 700B RUN 49 INTERMITTENT CO-FEED POTASSIUM $72.796827-17$ in $290 \mathrm{~g}_{30}$ oil $0.0405 w+K$-LAURATE in 50/50 IPA/HEPTANE

TEED, NL/H g Fo $128 \leftarrow$

TARGET TEMP,C $280 \leftarrow$

PRESSURE, psig $153 \leftarrow$

22
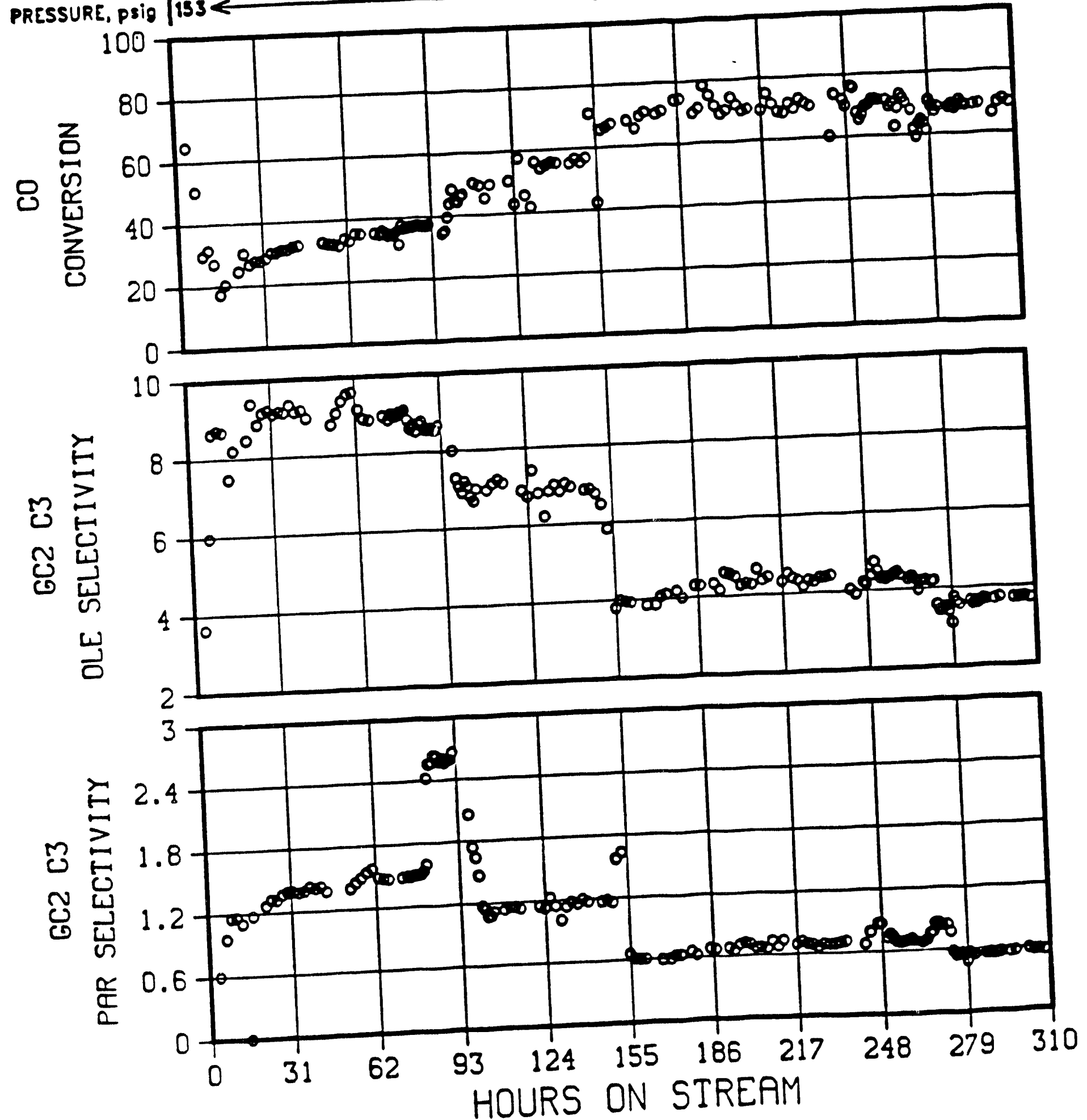


\section{FIGURE A-14}

PLT 700B RUN 49 INTERMITTENT CO-FEED POTASSIUM $72.796827-17$ in $290 \mathrm{~g} \mathrm{C}_{30}$ oil $0.0405 w+\% \mathrm{~K}$-LAURATE in 50/50 IPA/HEPTANE

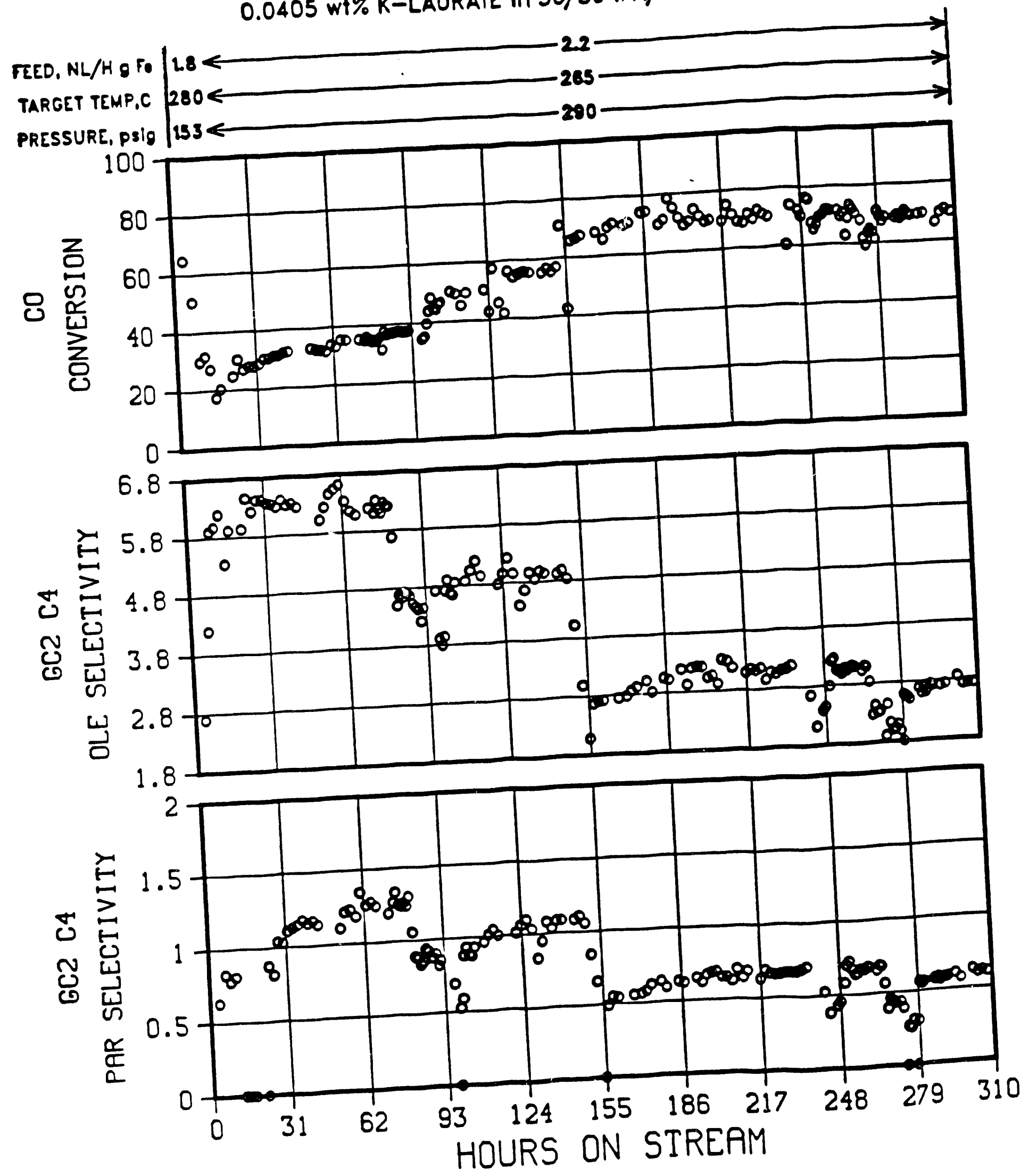




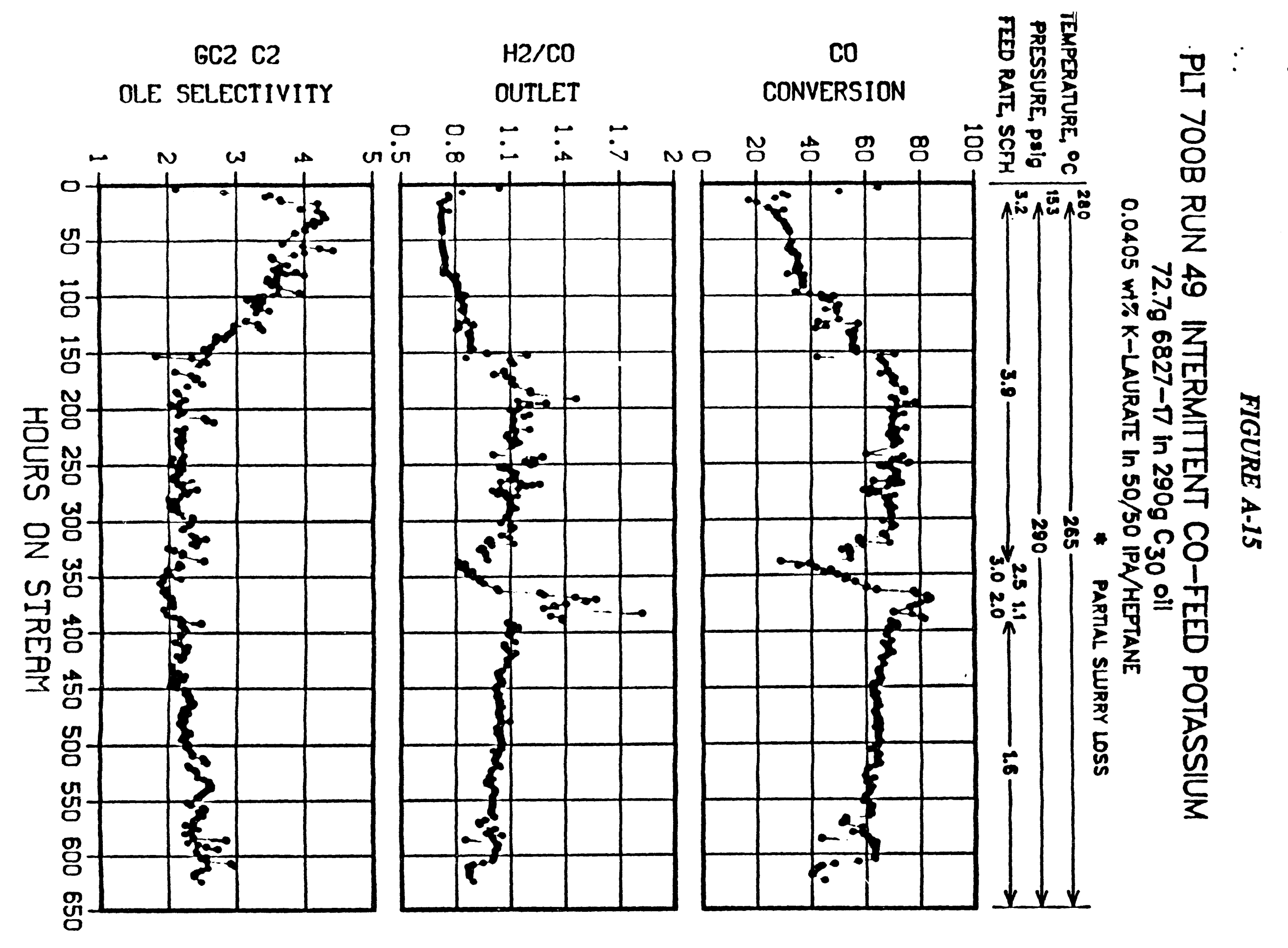




\section{FIGURE A-16}

\section{PLT 700B RUN 49 INTERMITTENT CO-FEED POTASSIUM $72.7 \mathrm{~g} 6827-77$ in $290 \mathrm{~g}_{30}$ oil \\ $0.0405 w+\%$ K-LAURATE in 50/50 IPAMEPTANE}

\begin{tabular}{l|l} 
TEMPERATURE, OC & 2 \\
PRESSURE, Psig & \\
FEED RATE, SCFH & 3
\end{tabular}
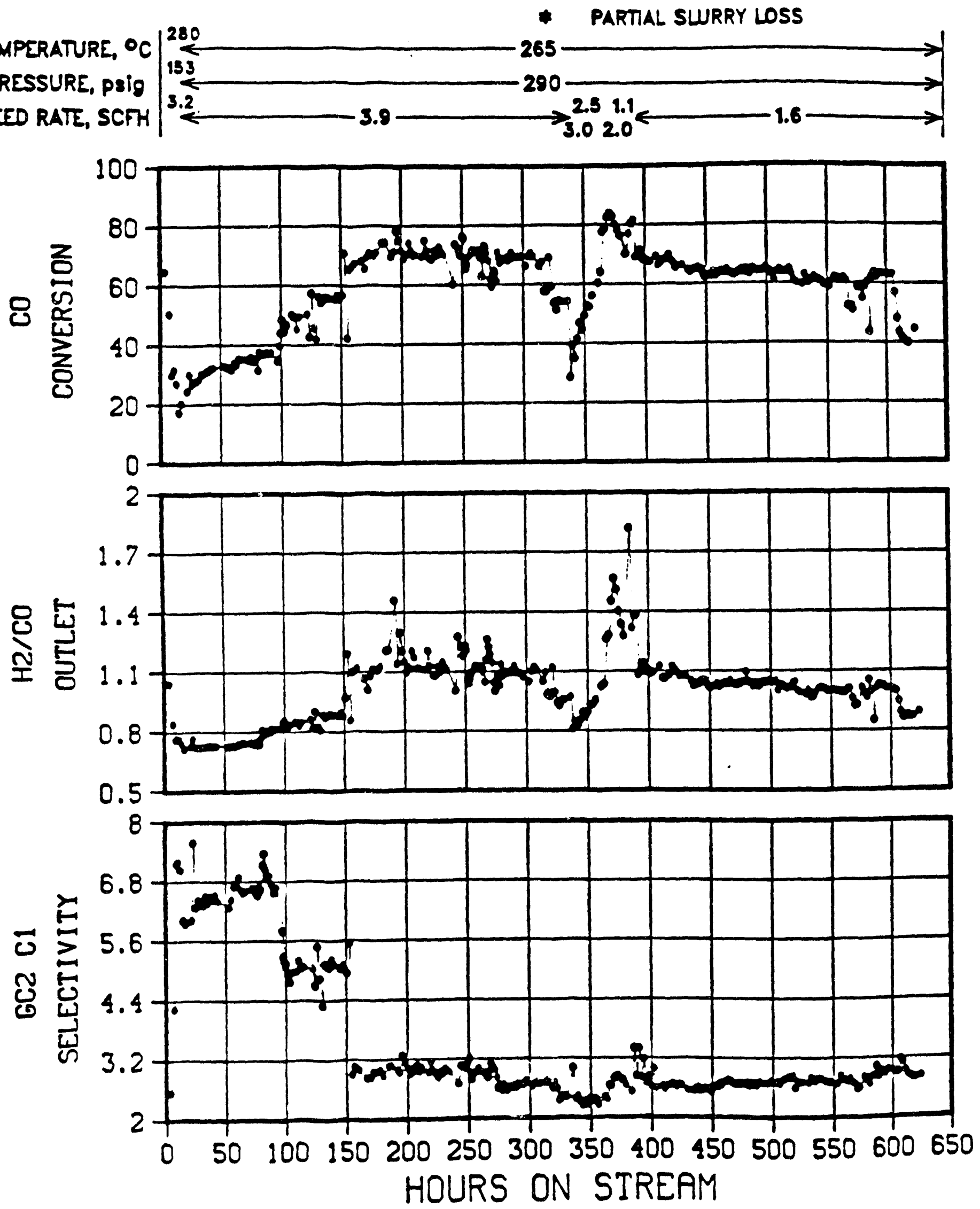


\section{FIGURE A-17}

PLT 700B RUN 49 INTERMITIENT CO-FEED POTASSIUM

$72.7 \mathrm{~g} 6827-7$ in $290 \mathrm{~g} \mathrm{C}_{30}$ oil

0.0405 wt\% K-LAURATE in 50,50 IPA HEPTANE
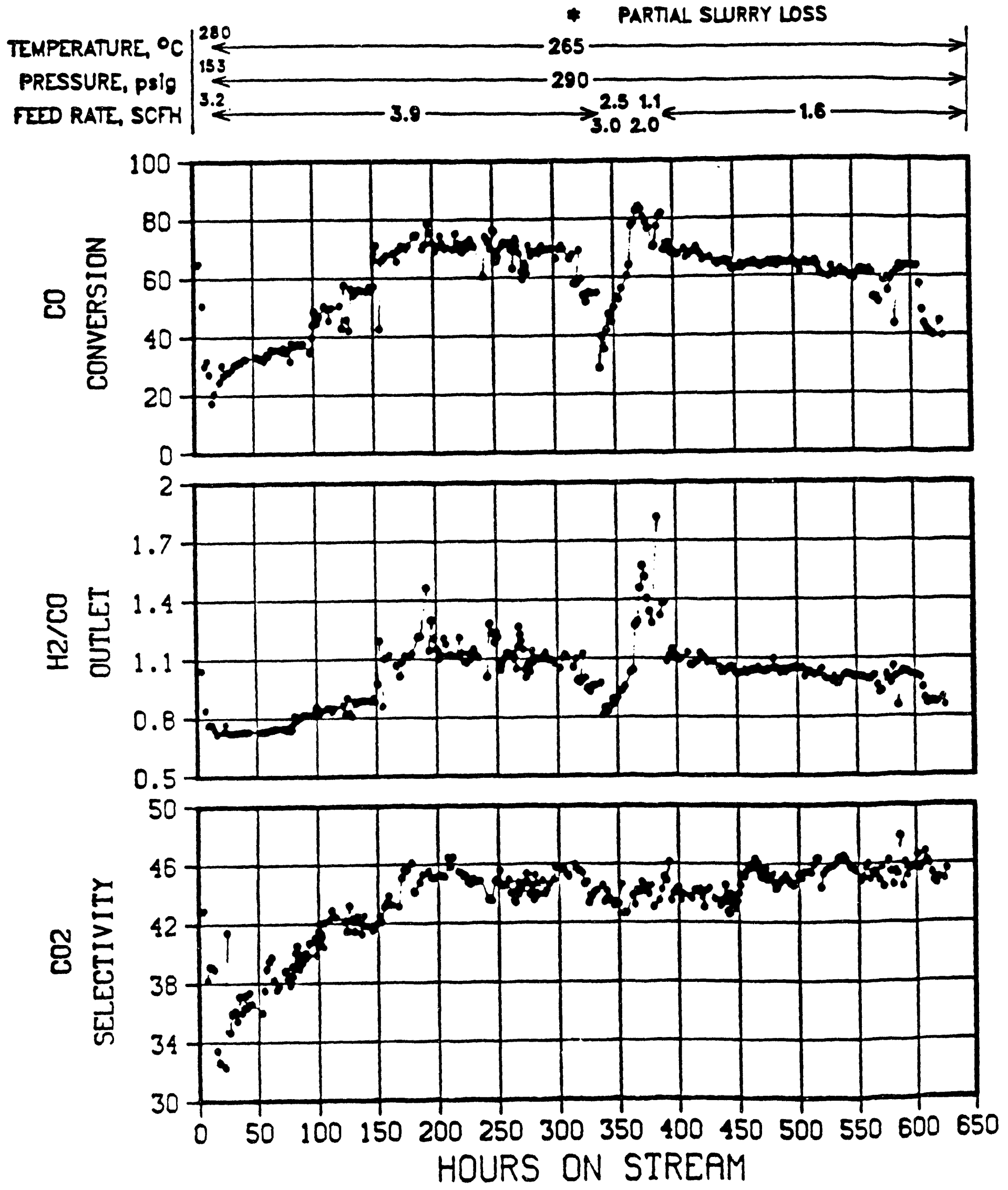
FIGURE A-18

$\because$

PLT 700B RUN 49 INTERMITTENT CO-FEED POTASSIUM

$72.7 \mathrm{~g} 6827-17$ in $290 \mathrm{~g} \mathrm{C}_{30}$ oil

$0.0405 w+\%$ K-LAURATE in 50/50 IPA/HEPTANE
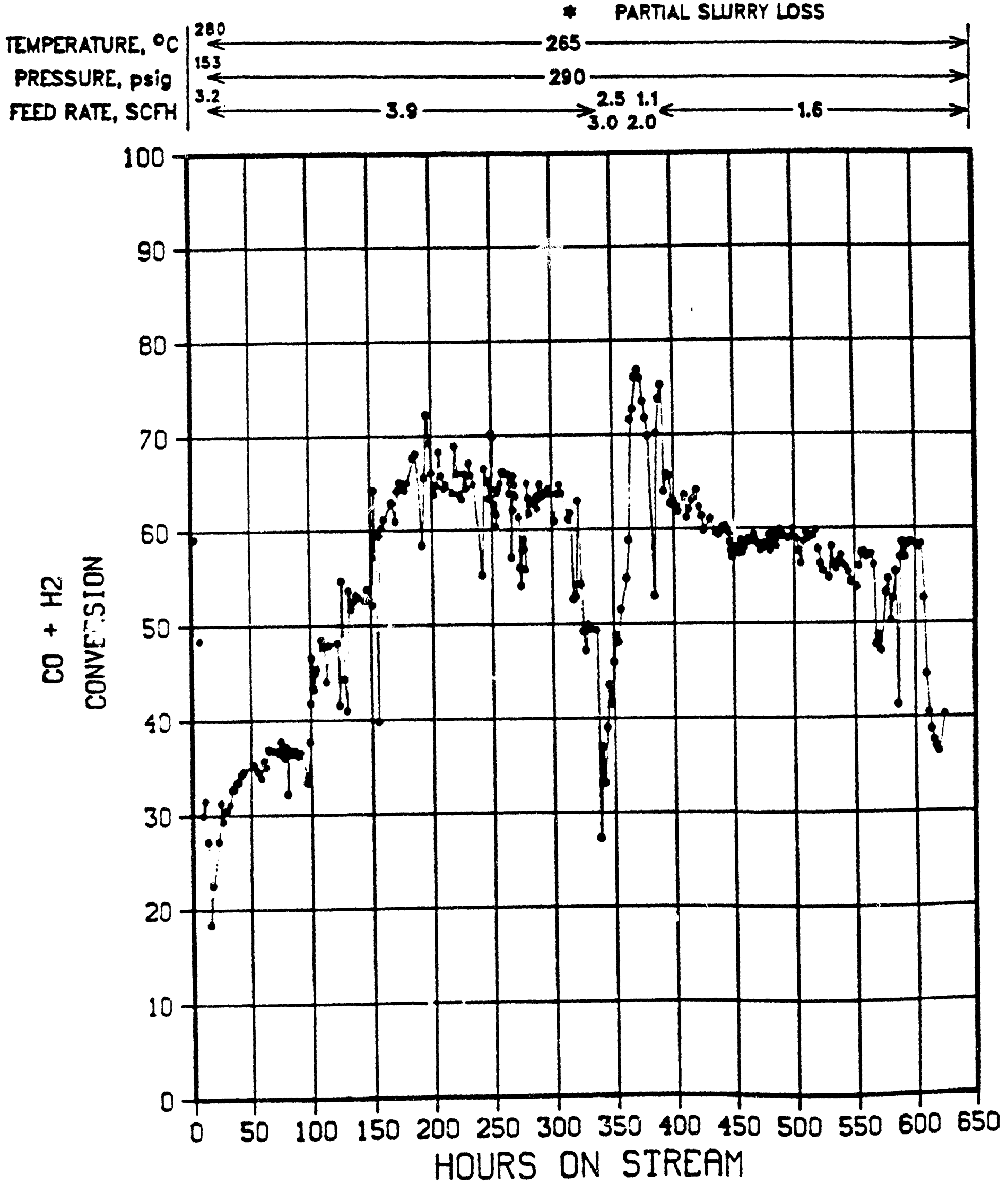
PLT 700B RUN 49 INTERMITIENT CO-FEED POTASSIUM

$72.7 \mathrm{~g} 6827-77$ in $290 \mathrm{~g} \mathrm{C}_{30}$ oil

$0.0405 w+\%$ K-LAURATE in 50/50 IPA/HEPTANE
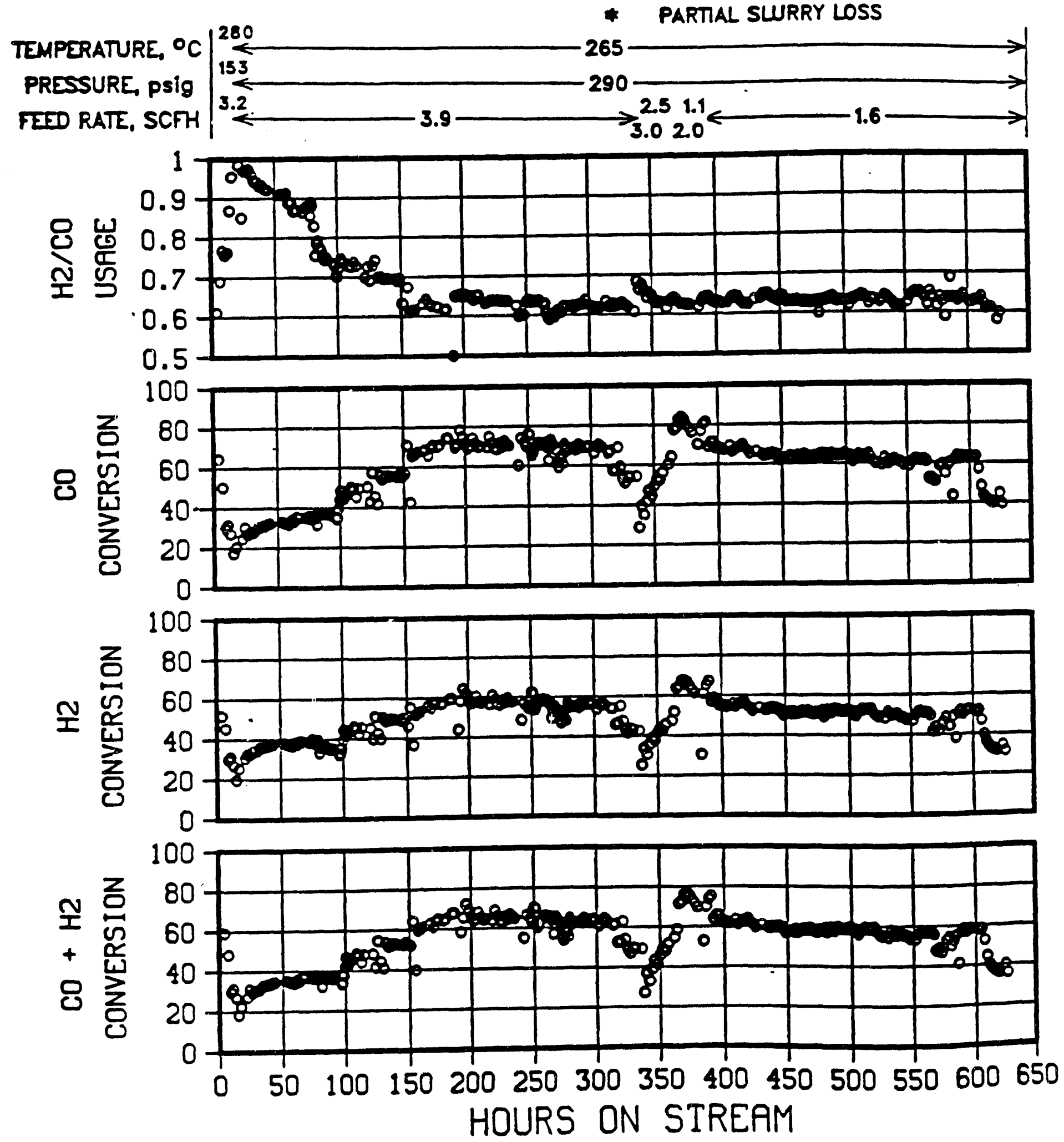
PLT 700B RUN 49 INTERMITTENT CO-FEED POTASSIUM
$72.7 \mathrm{~g} 6827-17$ in $290 \mathrm{~g} \mathrm{C}_{30}$ oil

0.0405 wt\% K-LAURATE in 50/50 IPA/HEPTANE

TEMPERATURE, ${ }^{\circ} \mathrm{C} \mid$
PRESSURE, pSIg
FEED RATE, SCFH

* partial slurry loss
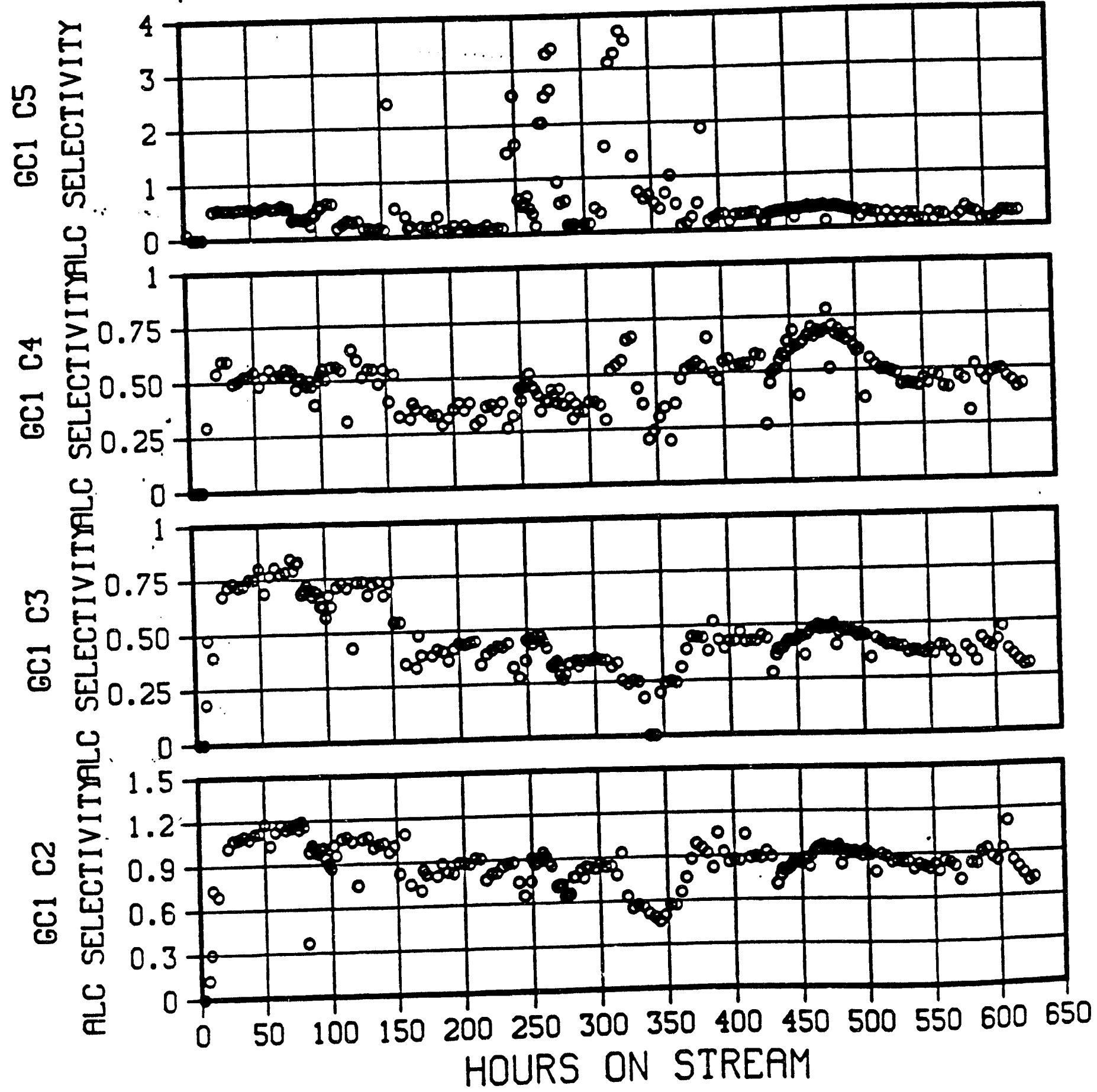
FIGURE A-21

Effect of K Level on Cat Performance

Run 49

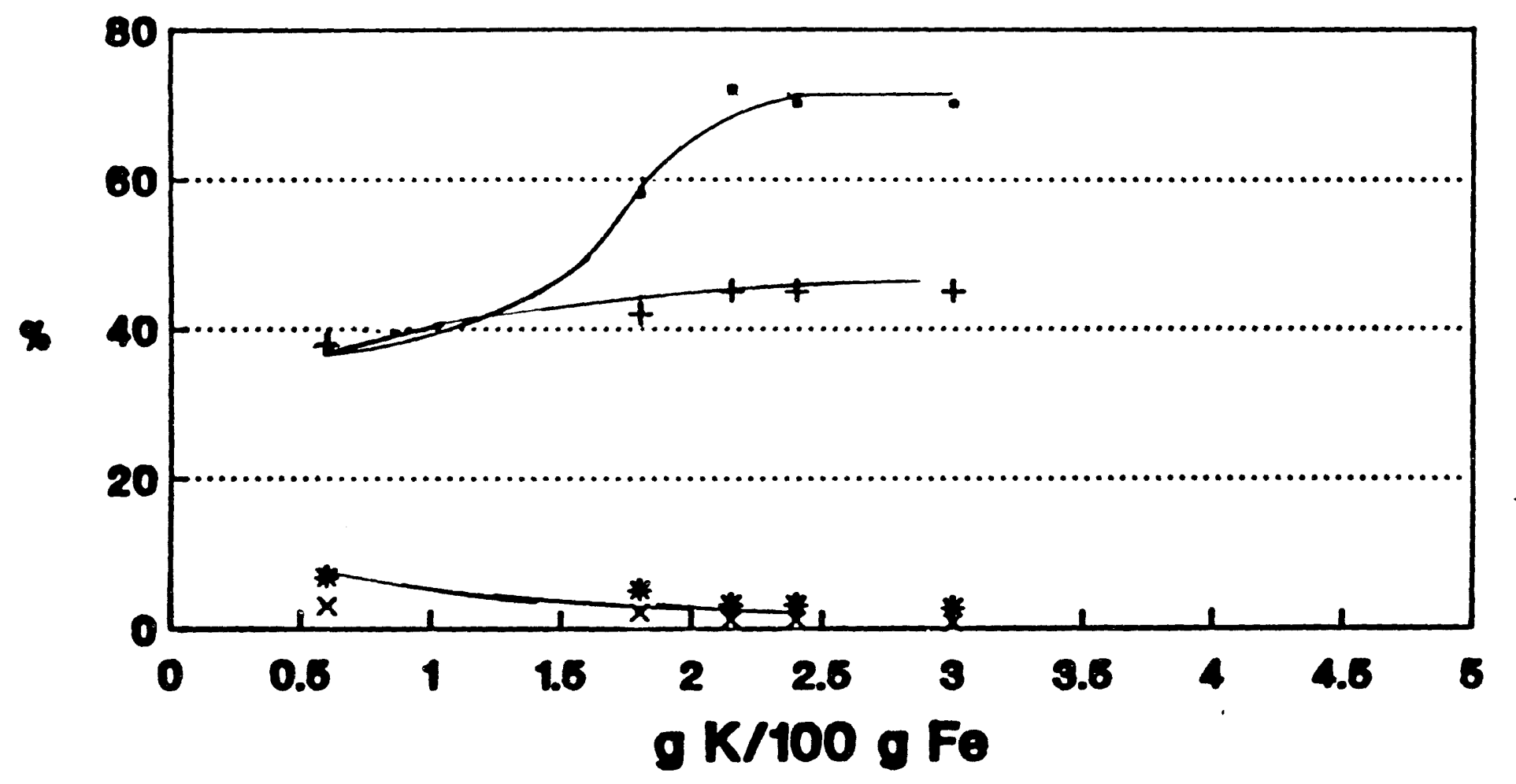

- co conv

$+\quad 60280100$

* Mothane soleo

$\times$ Ethane 80100 
FIGURE A-22

PLT 700B RUN 47 BASEUNE FOR PRETREATMENT STUDY MATRIX $72.7 \mathrm{~g} 6616-160$ in $290 \mathrm{~g} \mathrm{C}_{30}$ oll

FEED, NLAH g Fo TARGET TEMP,C PRESSURE, P3ig $153 \leftarrow$ $\mathrm{H}_{2}: \mathrm{CO}$ in feed $=0.7,1100 \mathrm{rpm}$

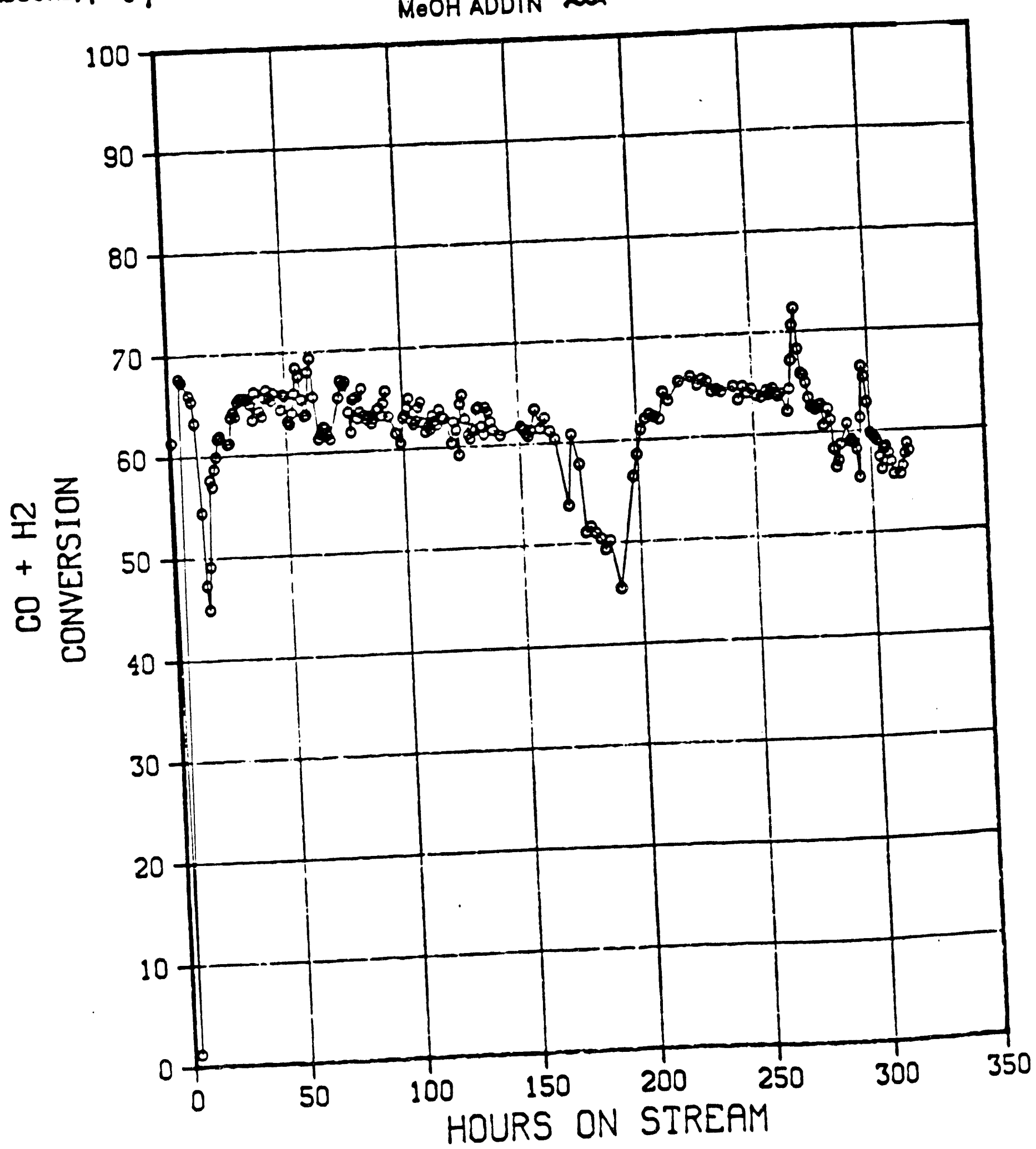




\section{FIGURE A-23}

$\therefore$ PLT 700B RUN 47 BASEUNE FOR PRETREATMENT STUDY MATRIX $72.7 \mathrm{~g} 6616-160$ in $290 \mathrm{~g}_{30}$ oil

$\mathrm{H}_{2}: \mathrm{CO}$ in feod $=0.7,1100 \mathrm{rpm}$

\begin{tabular}{l|l} 
FEED, NL/H g Fo & $2.0 \leftarrow$ \\
TARGET TEMP,C & $280 \leftarrow$ \\
PRESSURE, PSIg & $153 \leftarrow$
\end{tabular}

2.4

265

290

$\mathrm{MeOH}$ ADDTN m
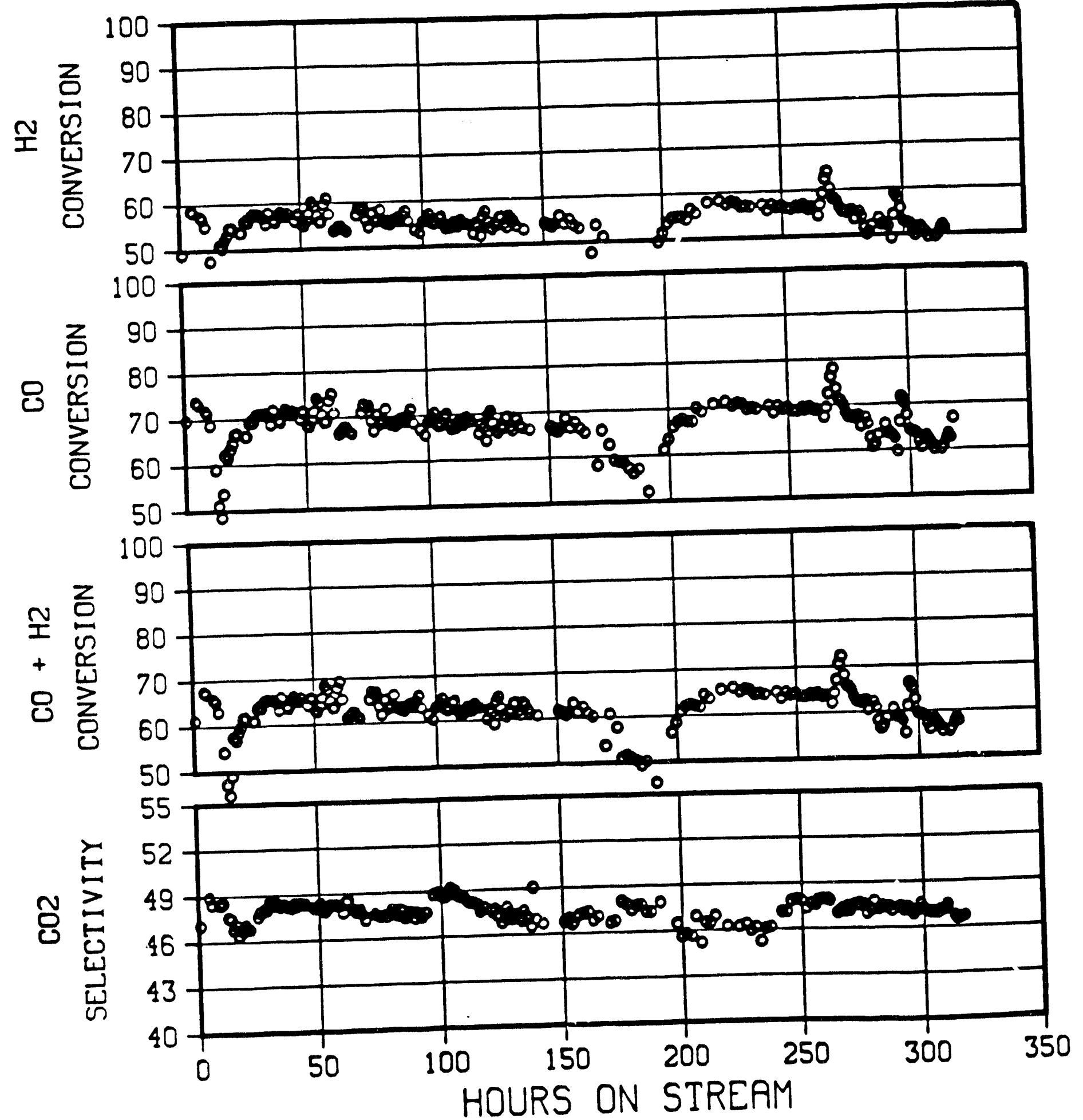


\section{FIGURE A-24}

FIGURE A-24
PLT 700B RUN 47 BASEUNE FOR PRETREATMENT STUDY MATRIX
$72.7 \mathrm{~g} 6616-160$ in $290 \mathrm{~g} \mathrm{C}_{30}$ oll $\mathrm{H}_{2}: \mathrm{CO}$ in foed $=0.7,1100 \mathrm{mpm}$

\begin{tabular}{c|l} 
FED, NLAH g FO & $2.0<$ \\
TARGET TEMP,C & $280 \mathrm{~K}$ \\
PRESSURE, PSIg & $153<$
\end{tabular}

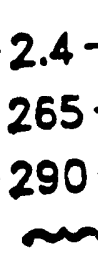

MeOH ADDTN m

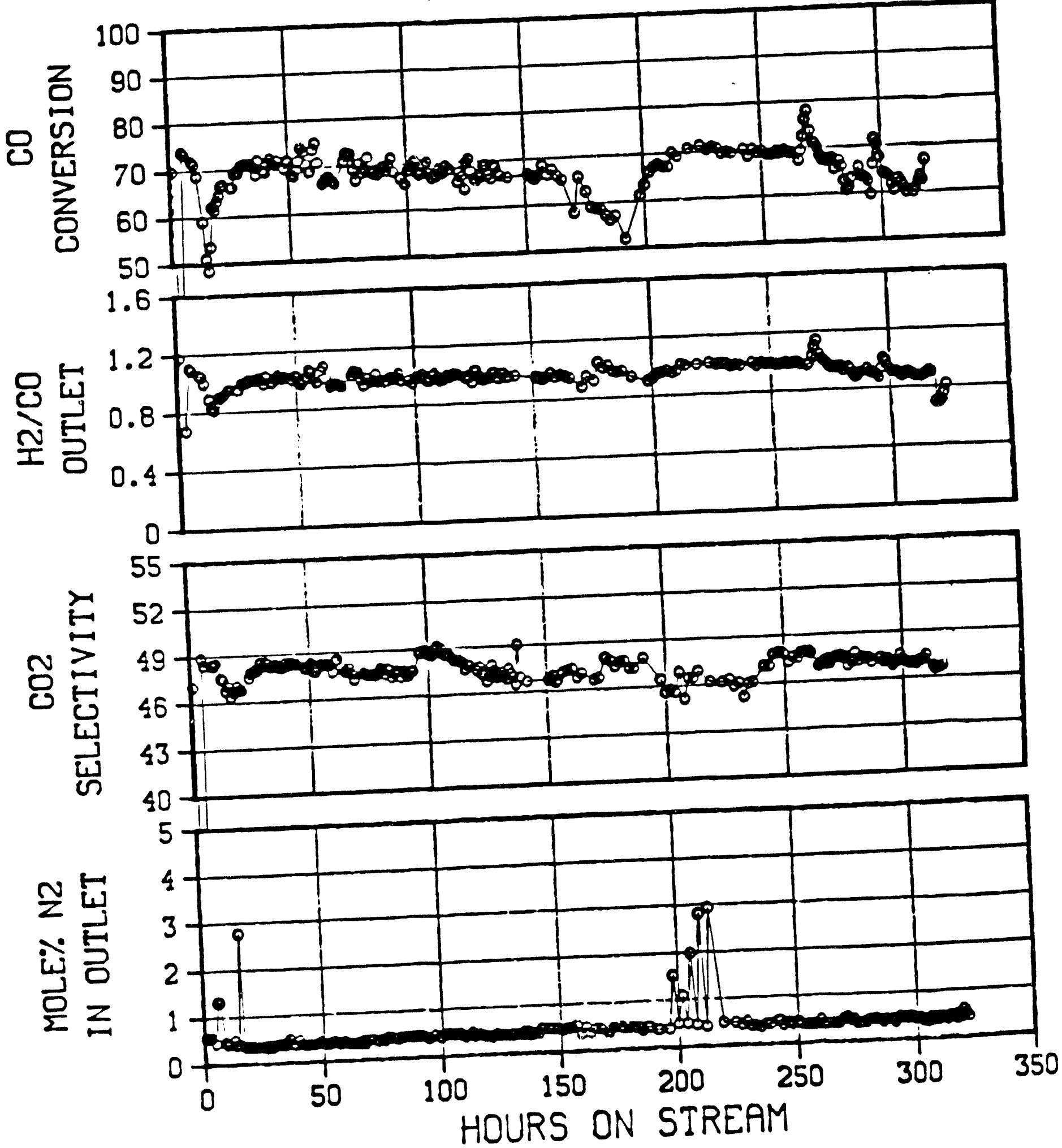


$\therefore$ PLT 700B RUN 47 BASEUNE FOR PRETREATMENT STUDY MATRIX $72.7 \mathrm{~g} 6616-160$ in $290 \mathrm{~g} \mathrm{C}_{30}$ oll $\mathrm{H}_{2}: \mathrm{CO}$ in food $=0.7,1100 \mathrm{rpm}$

\begin{tabular}{l|l} 
FEDD, NLAH O FE & $2.0 \leftarrow$ \\
TARGET TEMP.C & $280 \leftarrow$ \\
PRESSURE, PSIO & $153 \leftarrow$
\end{tabular}

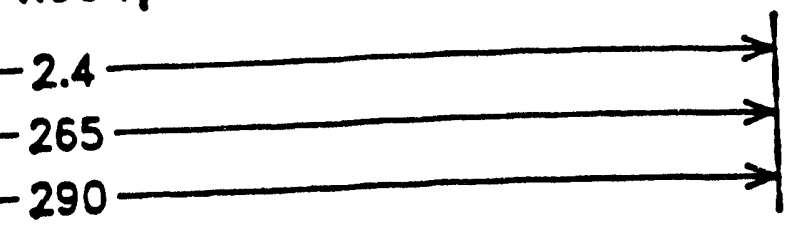

MeOH ADDTN m

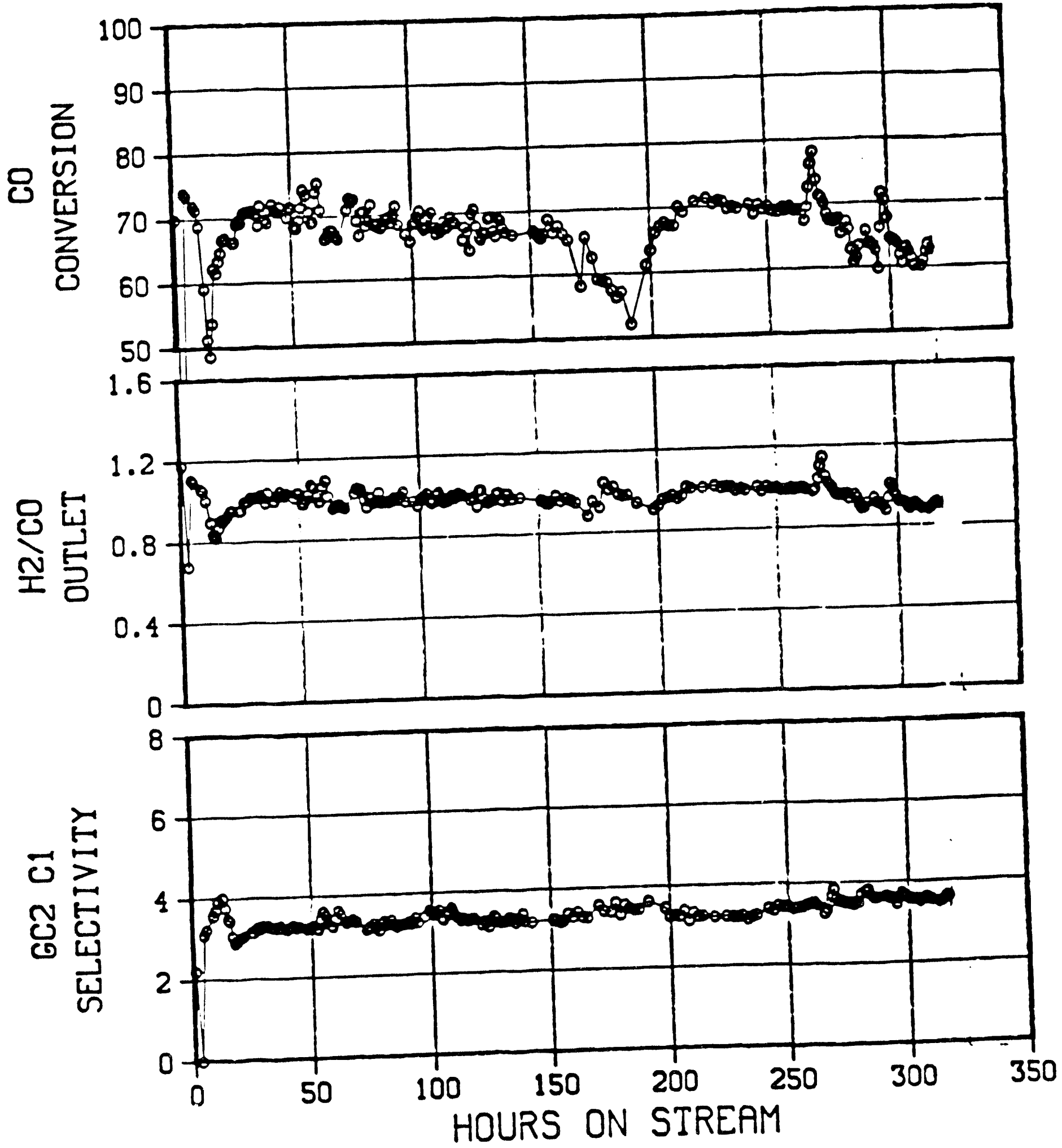




\section{FIGURE A-26}

PLT 700B RUN 47 BASEUNE FOR PRETREATMENT STUDY MATRIX $72.7 \mathrm{~g} 6616-160$ in $290 \mathrm{~g}_{30}$ oll $\mathrm{H}_{2}: \mathrm{CO}$ in food $=0.7,1100 \mathrm{rpm}$

FED, NL/H g Fo $2.0 \leftarrow$ TARGET TEMP,C PRESSURE, PSIg $153 \leftarrow$
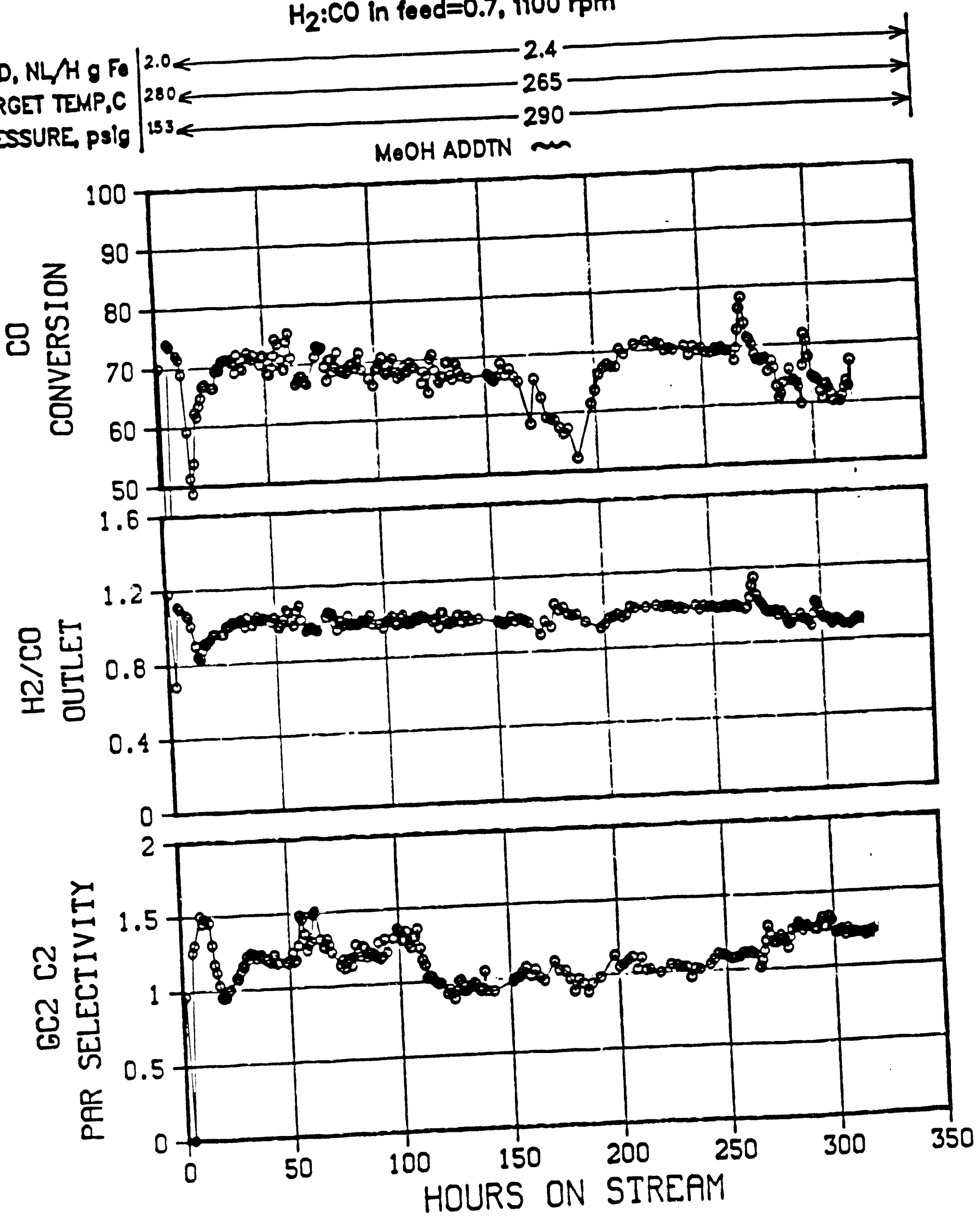
$\therefore$

\section{FIGURE A-27}

PLT 700B RUN 47 BASEUNE FOR PRETREATMENT STUDY MATRIX $72.7 \mathrm{~g} 6616-160$ in $290 \mathrm{~g} \mathrm{C}_{30}$ oll $\mathrm{H}_{2}: \mathrm{CO}$ in feed $=0.7,1100 \mathrm{rpm}$

FEED, NL/H g Fo $2.0<$ TARGET TEMP,C $280<$

PRESSURE, PSIg $153<$
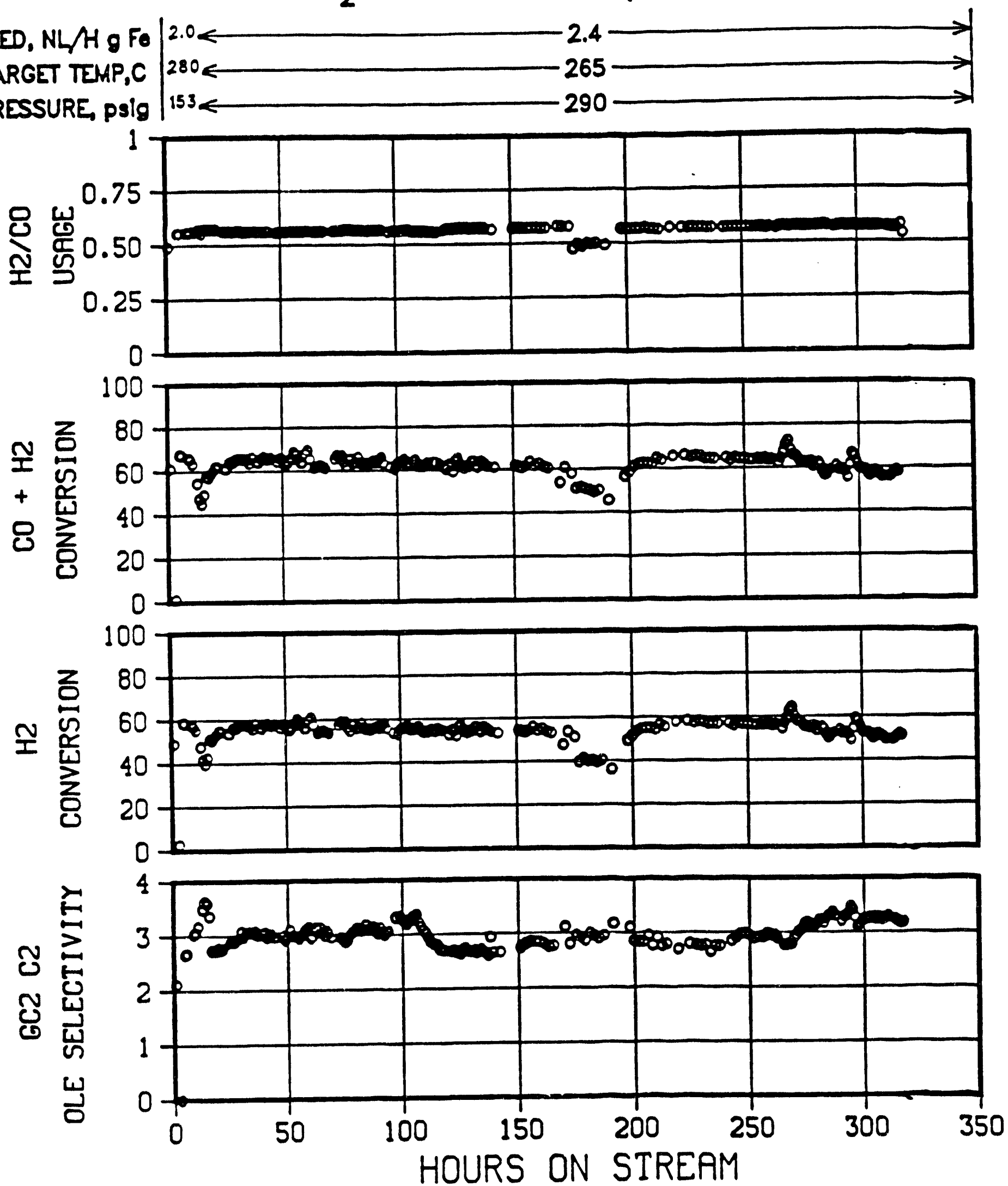

- PLT 700B RUN 47 BASEUNE FOR PRETREATMENT STUDY MATRIX
$72.7 \mathrm{~g} 6616-160$ in $290 \mathrm{~g} \mathrm{C}_{30}$ oil $\mathrm{H}_{2}: \mathrm{CO}$ in feed $=0.7,1100 \mathrm{rpm}$

FEED, NLA 9 FO TARGET TEMP,C PRESSURE, PSIg $153<$

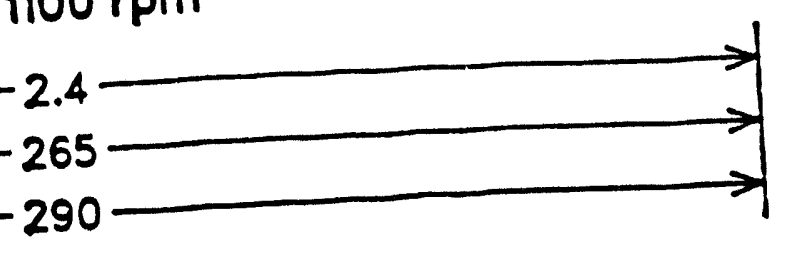

MeOH ADDTN

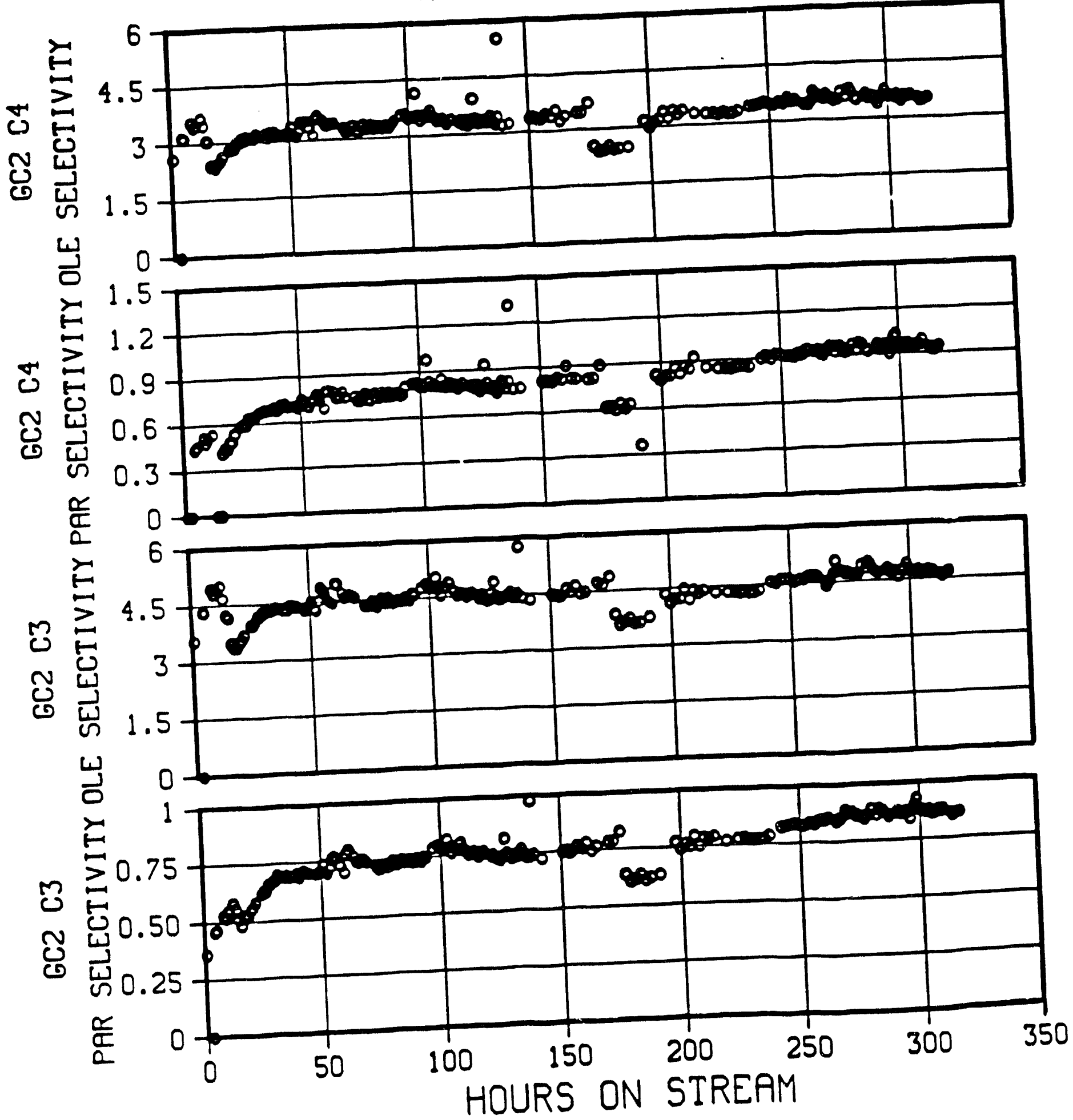




\section{FIGURE A-29}

PLT 700B RUN 47 BASEUNE FOR PRETREATMENT STUDY MATRIX $72.7 \mathrm{~g} 6616-160$ in $290 \mathrm{~g} \mathrm{C}_{30}$ oll $\mathrm{H}_{2}: \mathrm{CO}$ in foed $=0.7,1100 \mathrm{rm}$

\begin{tabular}{l|l} 
FEED, NL/H g Fo & $2.0<$ \\
TARGET TEMP,C & $280<$ \\
PRESSURE, PSIg & $153<$
\end{tabular}

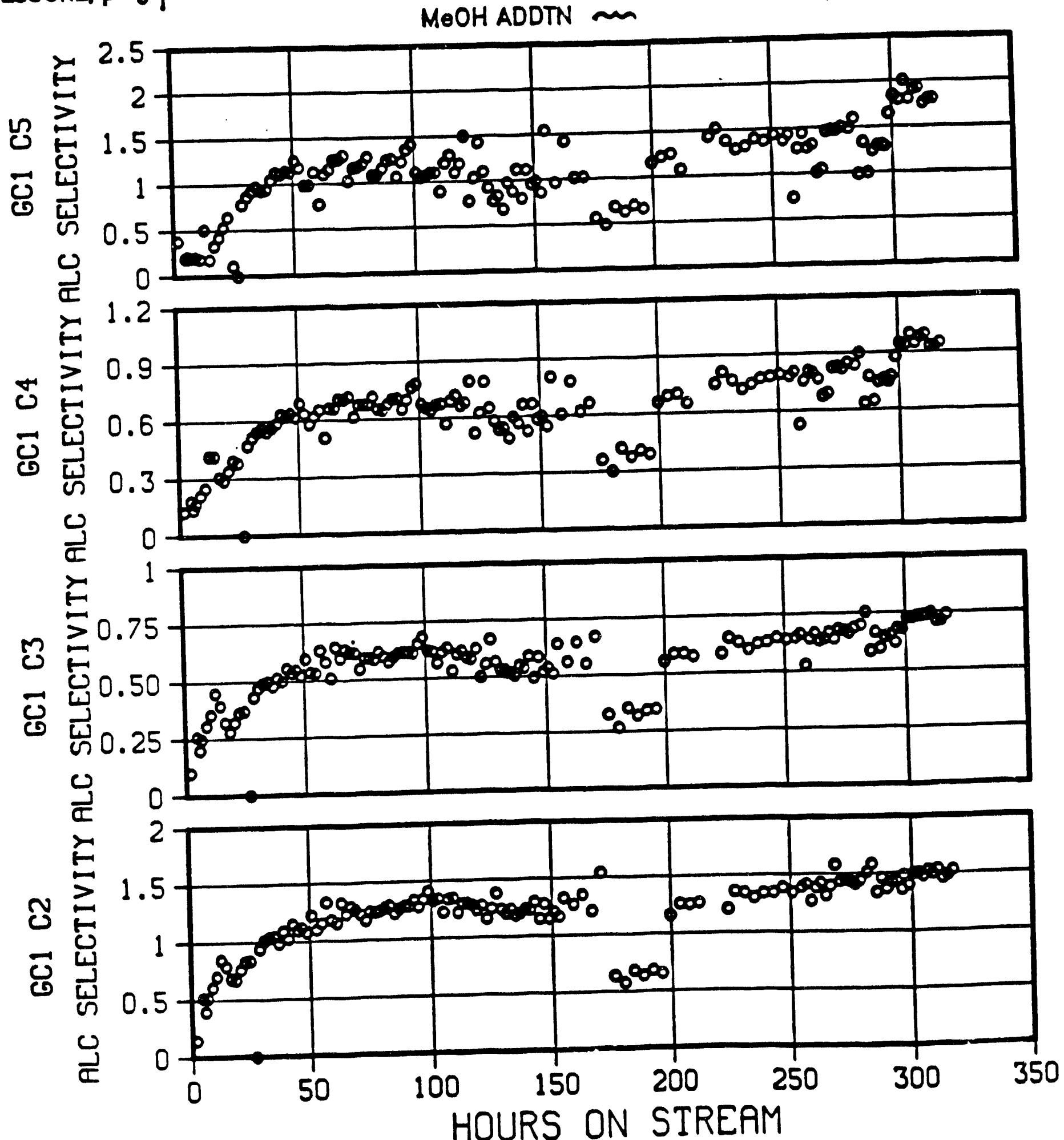


$\cdots$

PLT $700 B$ RUN 52 INTERMITTENT K-LAURATE CO-FEED

$72.7 \mathrm{~g} 6616-160$ in $290 \mathrm{~g}_{30}$ oll

475 pPm POTASSIUM in 50/50 IPA HEPTANE
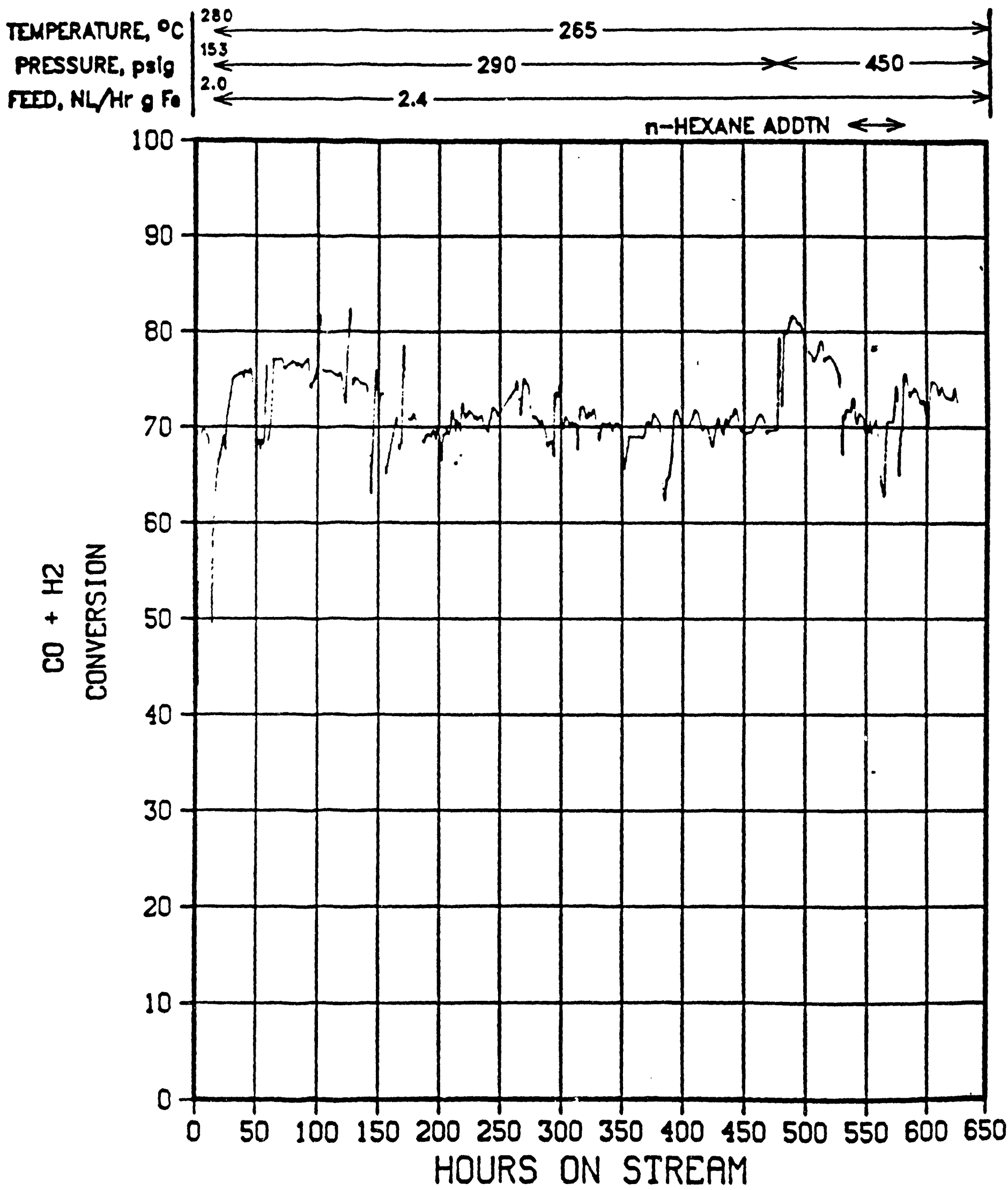


\section{FIGURE A-31}

- PLT 700B RUN 52 INTERMITTENT K-LAURATE CO-FEED

72.79 6616-160 in $290 \mathrm{~g} \mathrm{C}_{30}$ oil

475 pPM POTASSIUM in 50/50 IPA HEPTANE

TEMPERATURE, ${ }^{\circ} \mathrm{C} \mid$
PRESSURE, PSIg
FEED, NL/HT O Fo

265
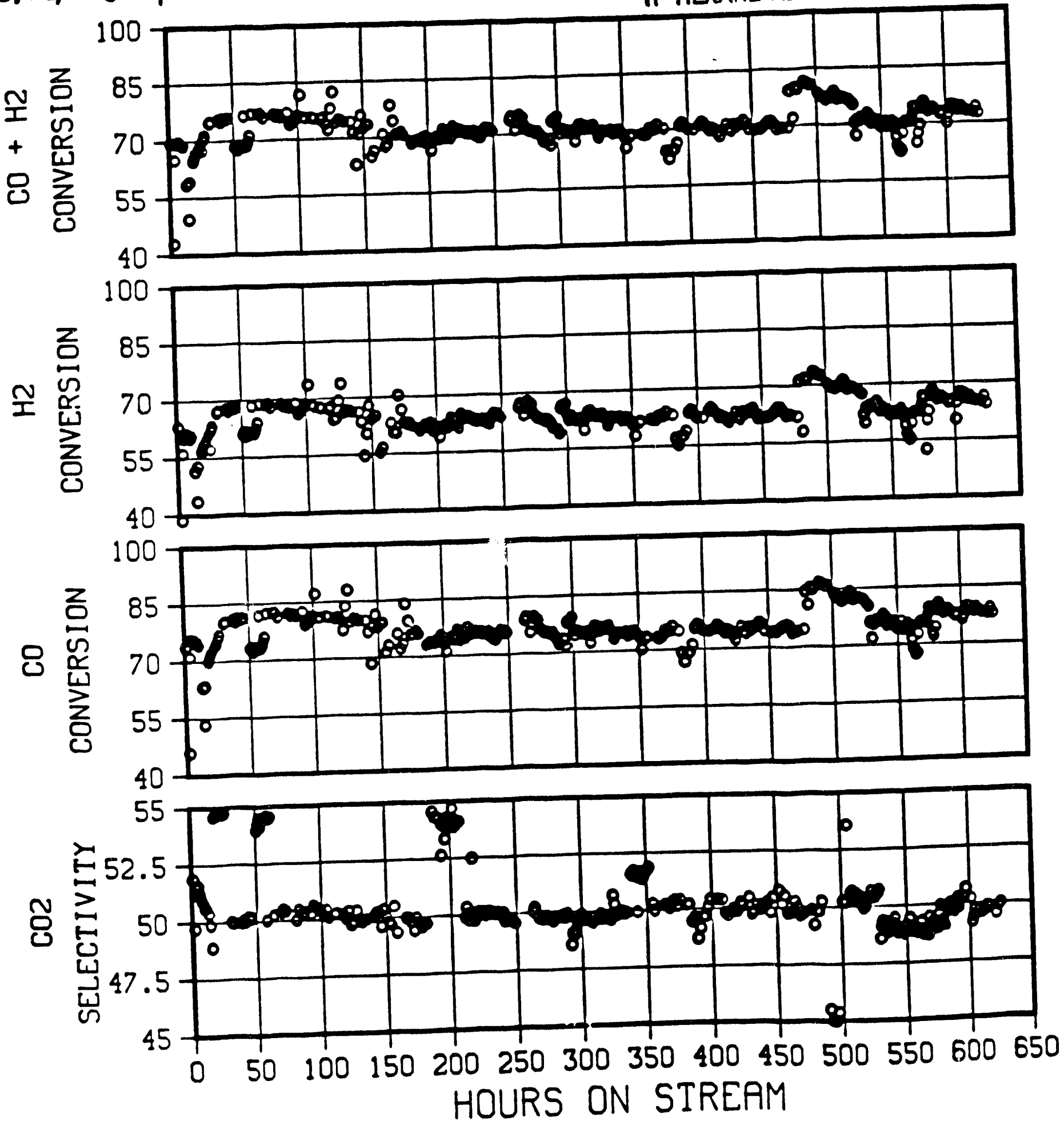


\section{FIGURE A-32}

$\because$ PLT 700B RUN 52 INTERMITIENT K-LAURATE CO-FEED 72.78 6616-160 in $290 \mathrm{~g} C_{30}$ oil $475 \mathrm{pPm}$ POTASSIUM in 50/50 IPA/HEPTANE

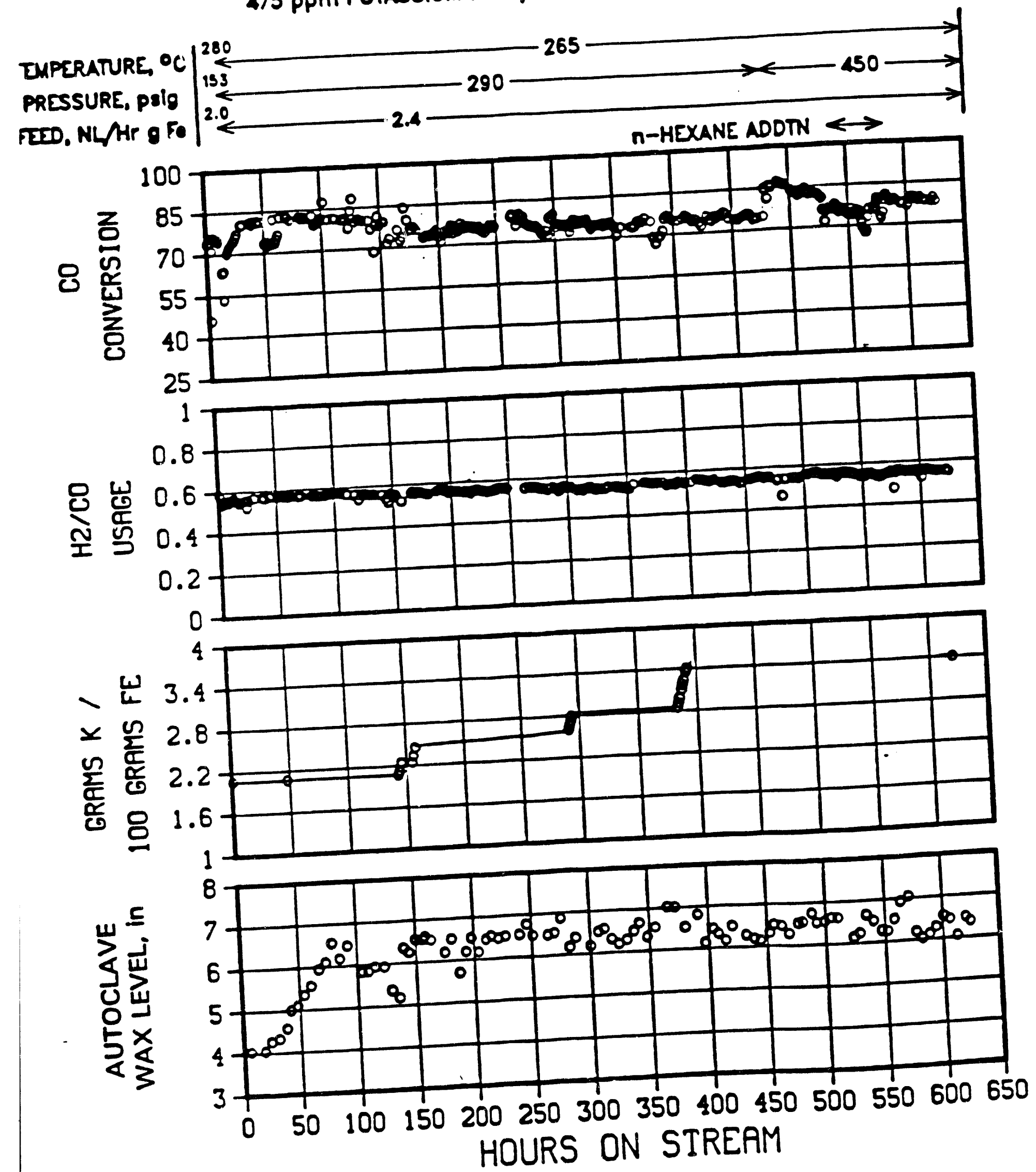


2

$\because \cdot \cdot$

FIGURE A-33

- PLT 700B RUN 52 INTERMITTENT K-LAURATE CO-FEED

$72.7 \mathrm{~g} 6616-16 \mathrm{~J}$ in $290 \mathrm{~g} \mathrm{C}_{30}$ oll

475 pPm POTASSIUM in 50/50 IPA HEPTANE
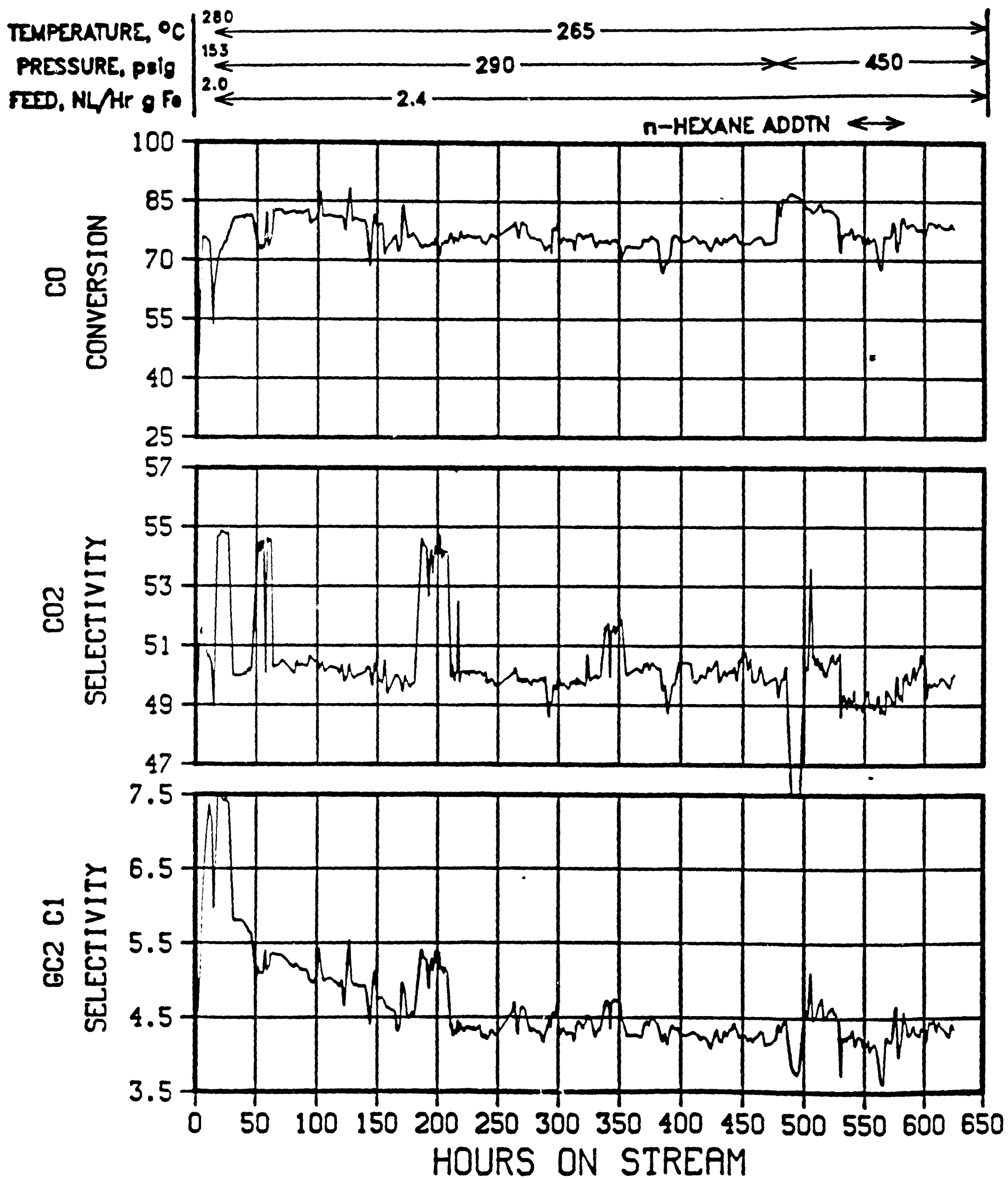


\section{-PLT 700B RUN 52 INTERMITTENT K-LAURATE CO-FEED \\ $72.7 \mathrm{~g} 6616-160$ in $290 \mathrm{~g} \mathrm{C}_{30}$ oil \\ 475 PPm POTASSIUM in 50/50 IPA HEPTANE}
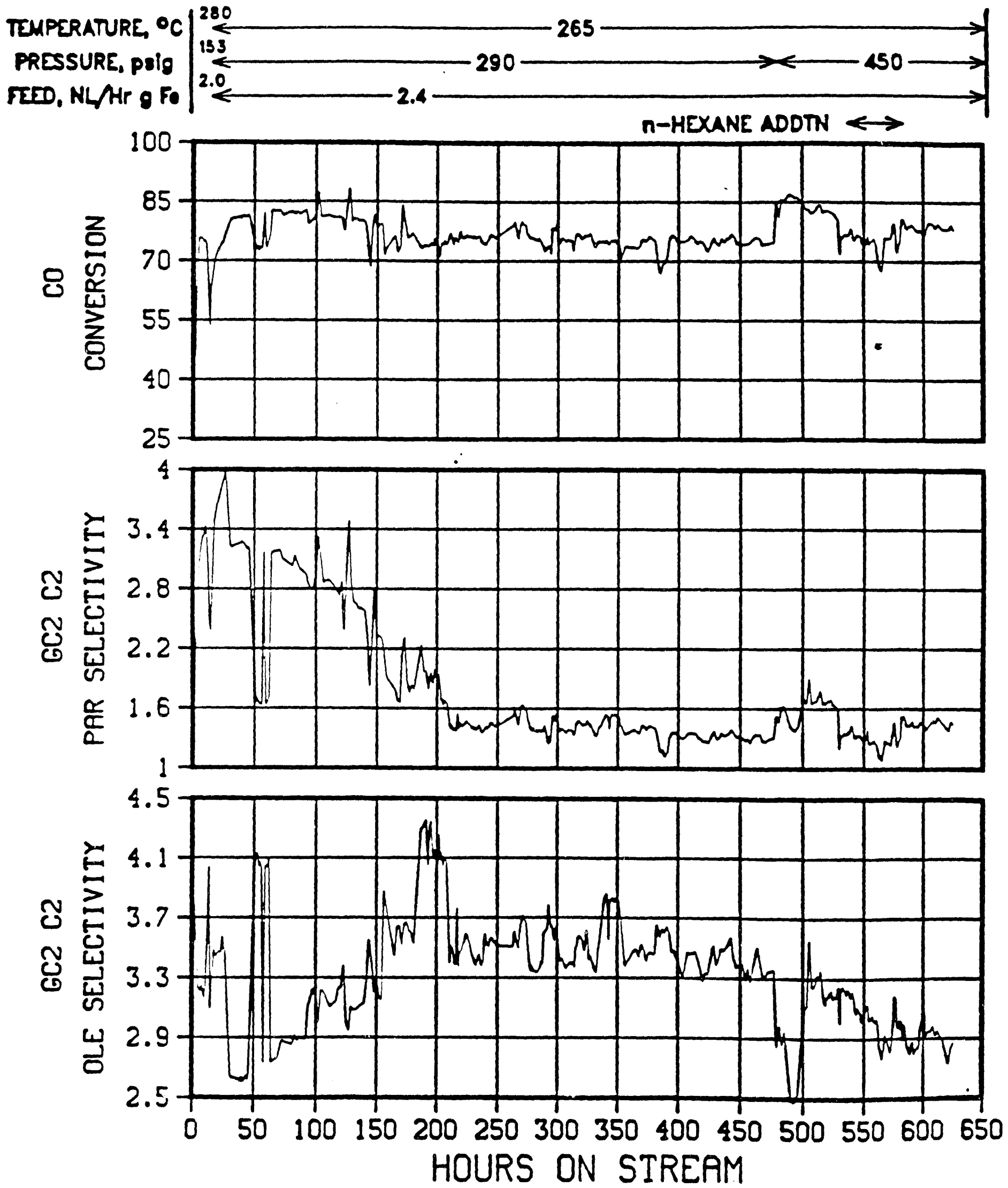


\section{PLT 700B RUN 52 INTERMITIENT K-LAURATE CO-FEED 72.7g 6616-160 in 290g $C_{30}$ oil $475 \mathrm{pPm}$ POTASSIUM in 50/50 IPAHEPTANE}
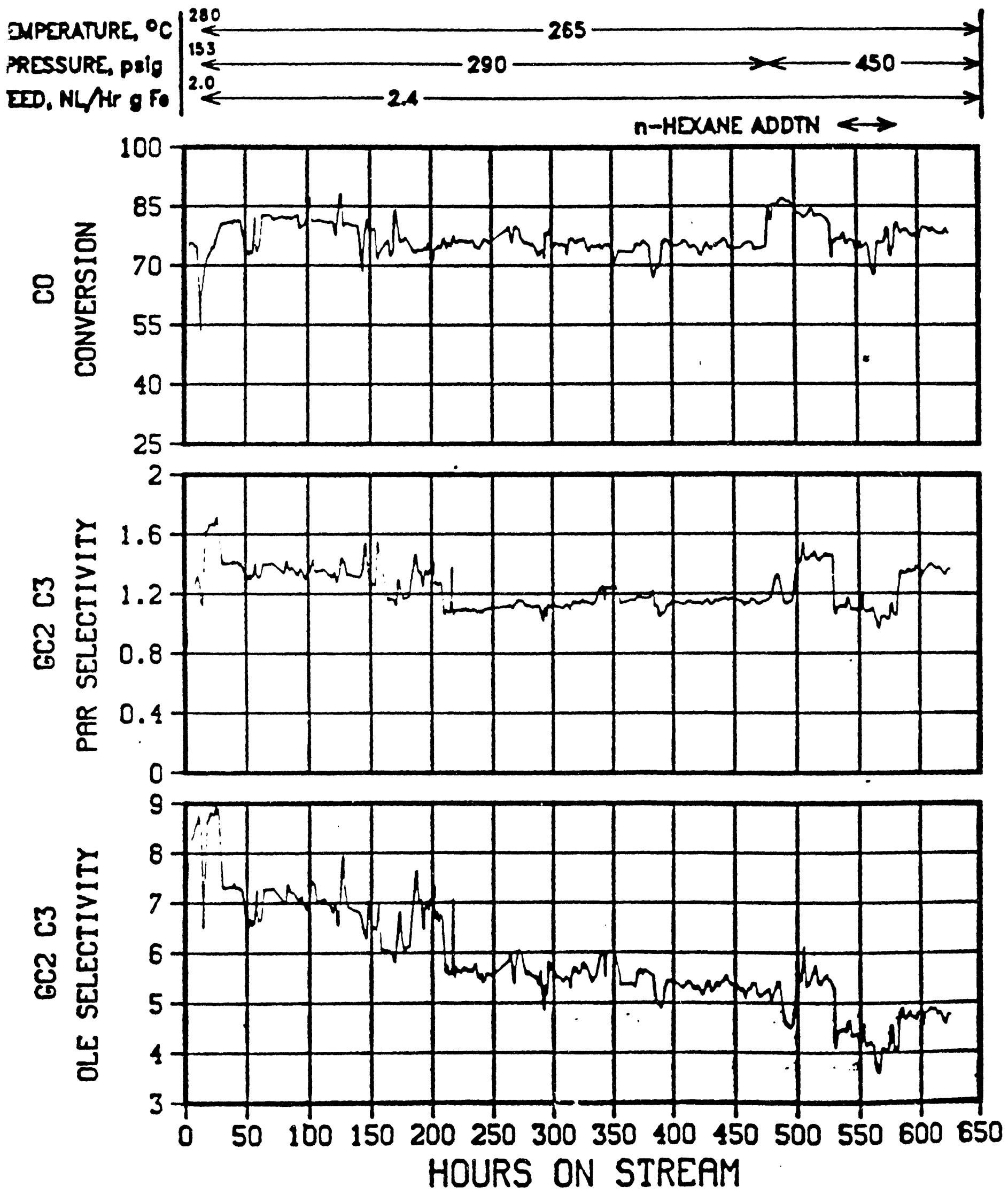
FIGURE A-36

$\because$ PLT 700B RUN 52 INTERMITIENT K-LAURATE CO-FEED

$72.7 \mathrm{~g} 6616-160$ in $290 \mathrm{~g} C_{30}$ ofl $475 \mathrm{pPm}$ POTASSIUM in 50/50 IPA/HETTANE
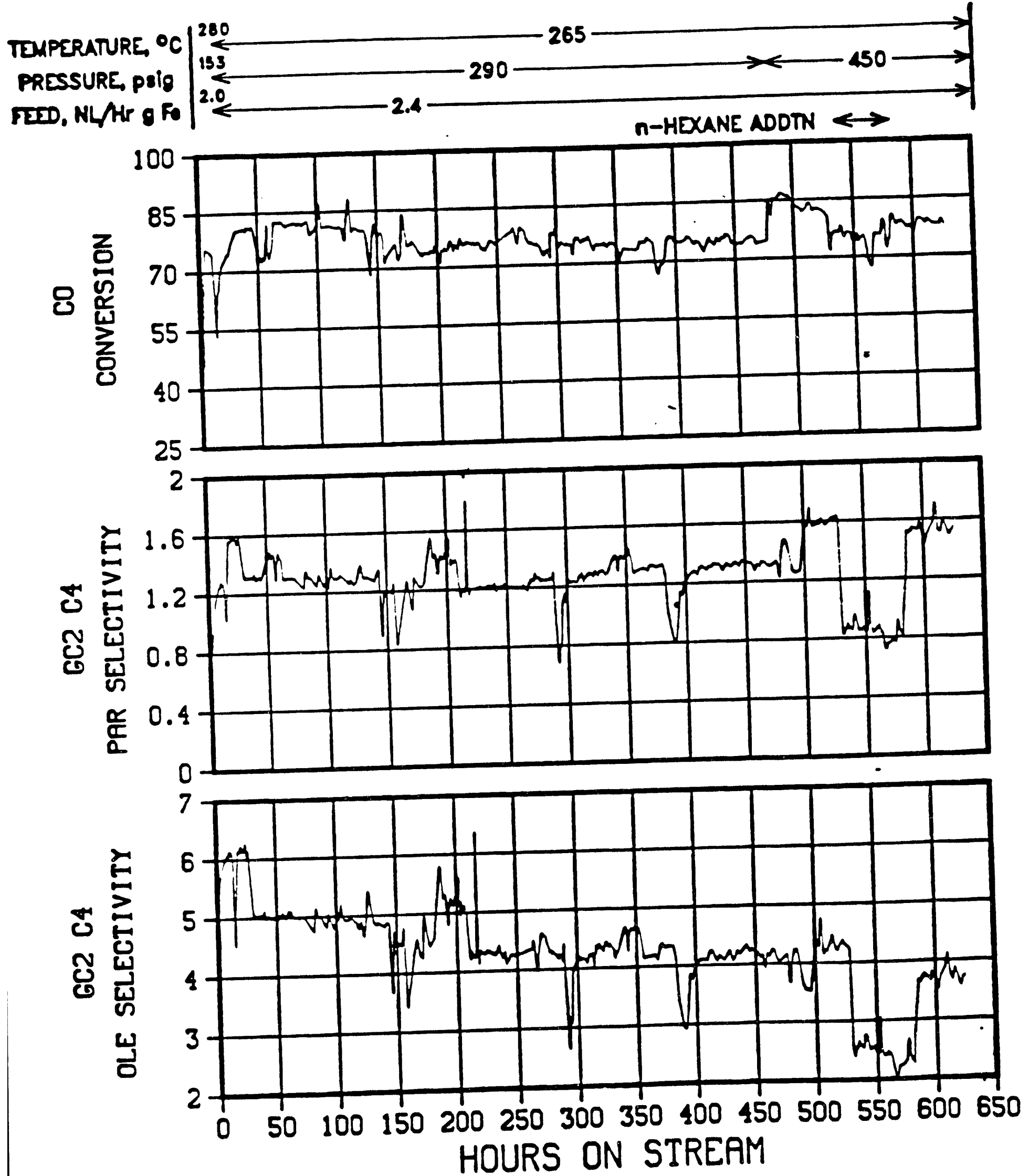
$\because$ PLT 700B RUN 52 INTERMITIENT K-LAURATE CO-FEED $72.7 \mathrm{~g} 6616-160$ in $290 \mathrm{~g} \mathrm{C}_{30}$ oil $475 \mathrm{pPm}$ POTASSIUM in 50/50 IPA/HEPTANE

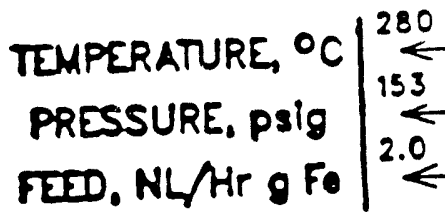

2.4
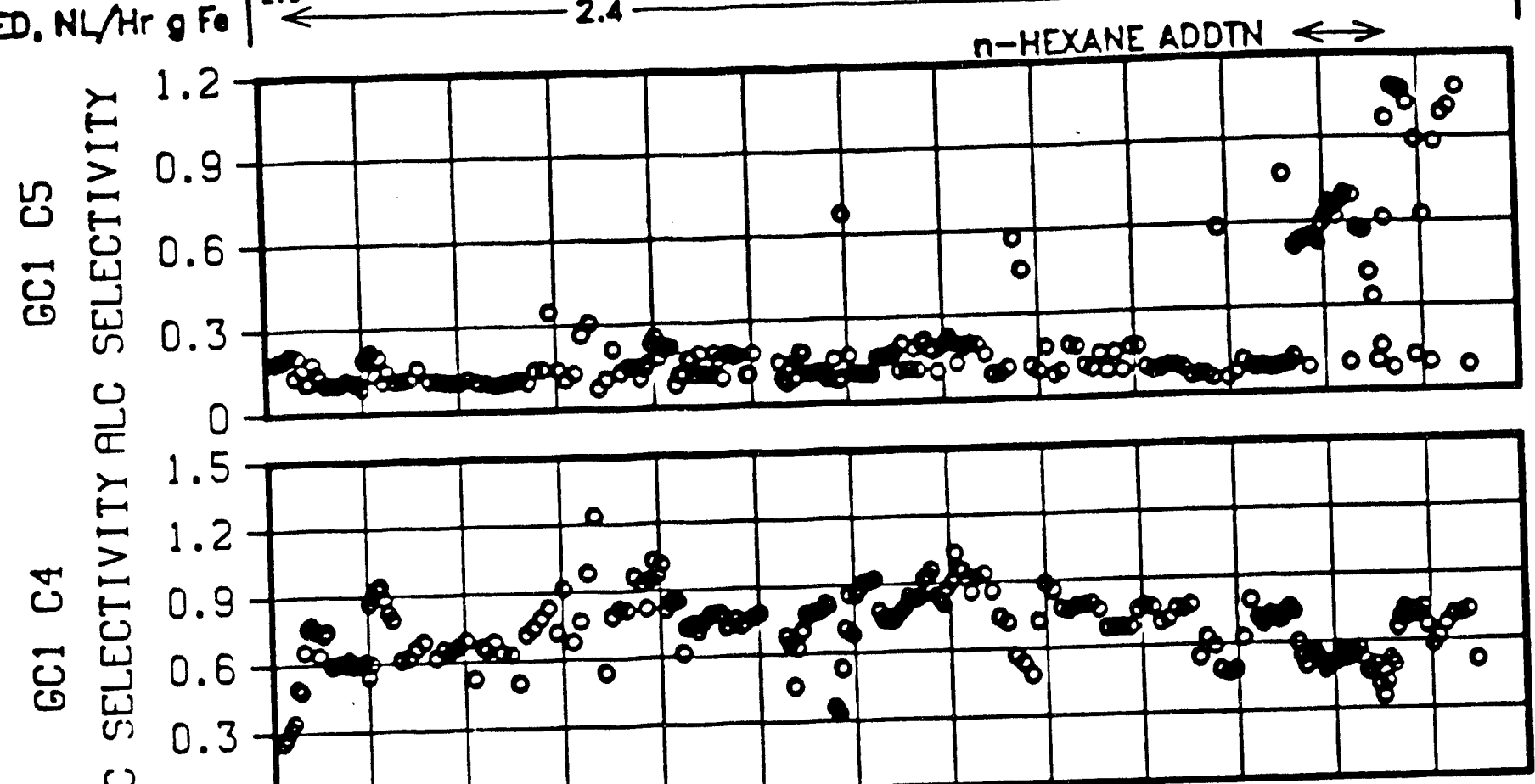

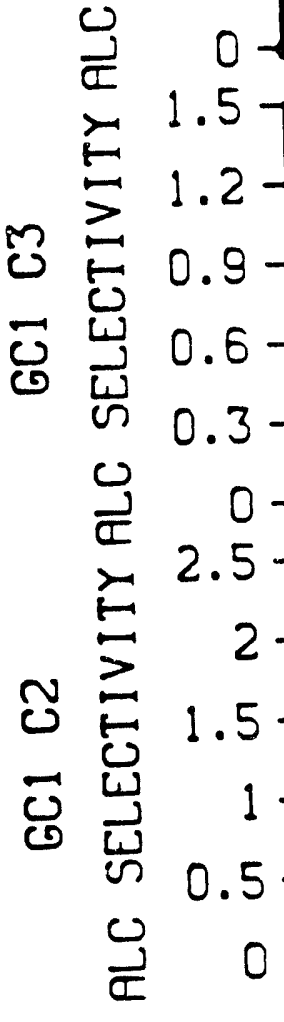


FIGURE A-38

Selec/Conv Plot, Various Cats

All Cats: Same Potassium Level

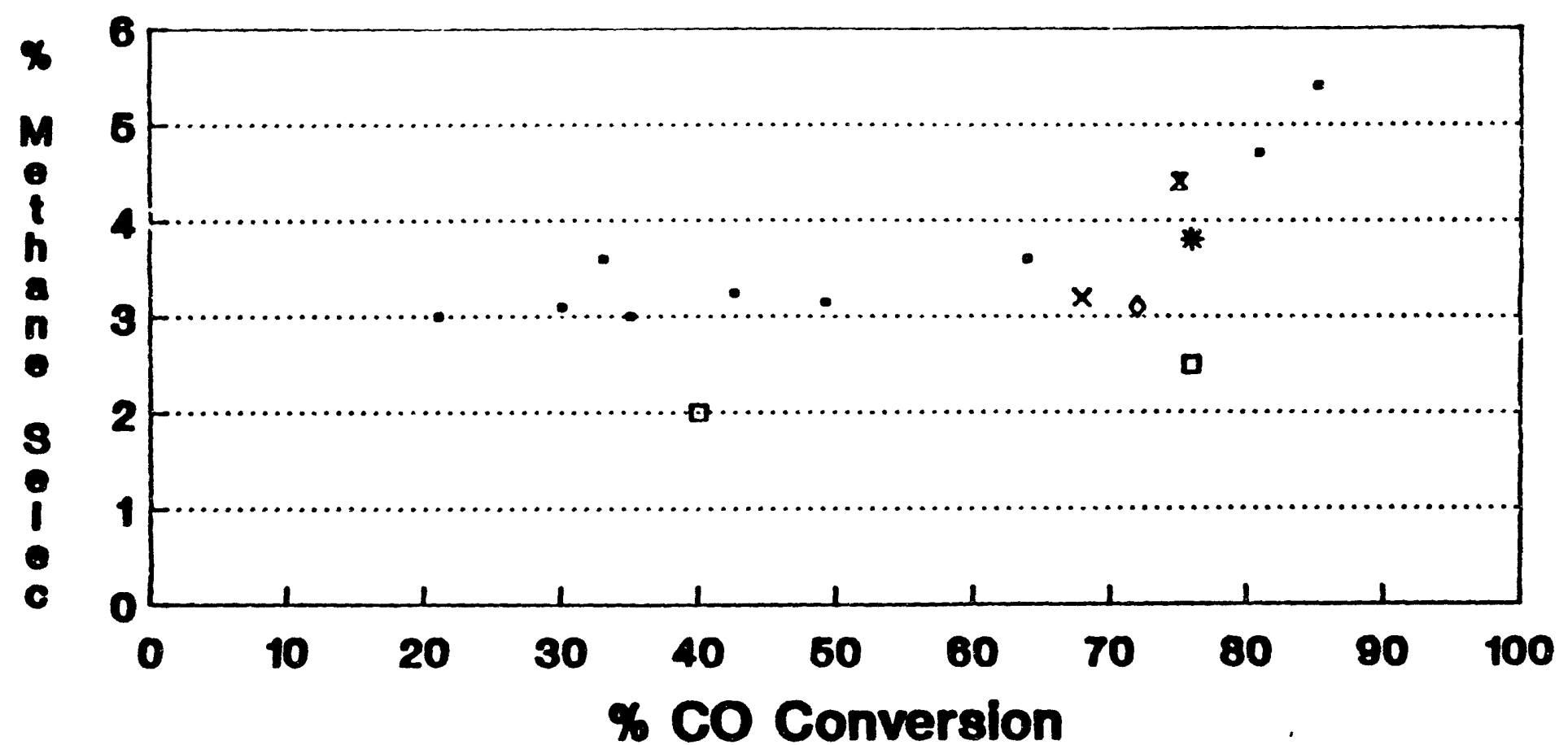

- RUN 48

$\times$ RUN 47
* RUN 37

- RUN 49
D RUN 46

$\times$ RUN 62 
FIGURE A-39

Selec/Conv Plot, Various Cats

All Cats: Same Potasslum Level

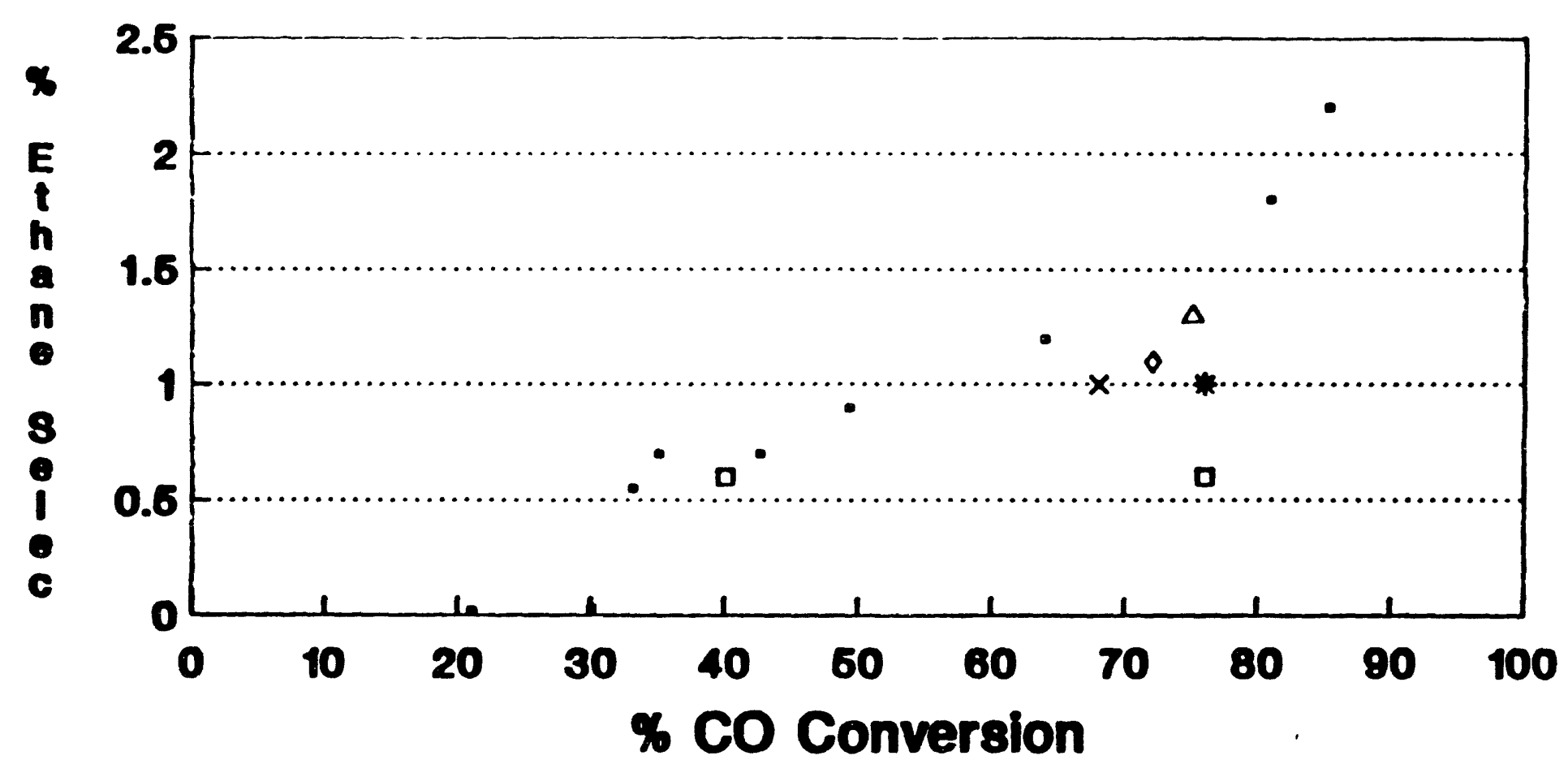

- AUN 48,

* RUN 37

- RUN 46

$\times$ AUN 47

- RUN 49

$\triangle$ RUN 43

A-43 data obtalnod at 268 and 206 dog C R-46 data obtained at 286 and 290 deg C 
FIGURE A-40

Selec/Conv Plot, Various Cats

All Cats: Same Potasslum Level

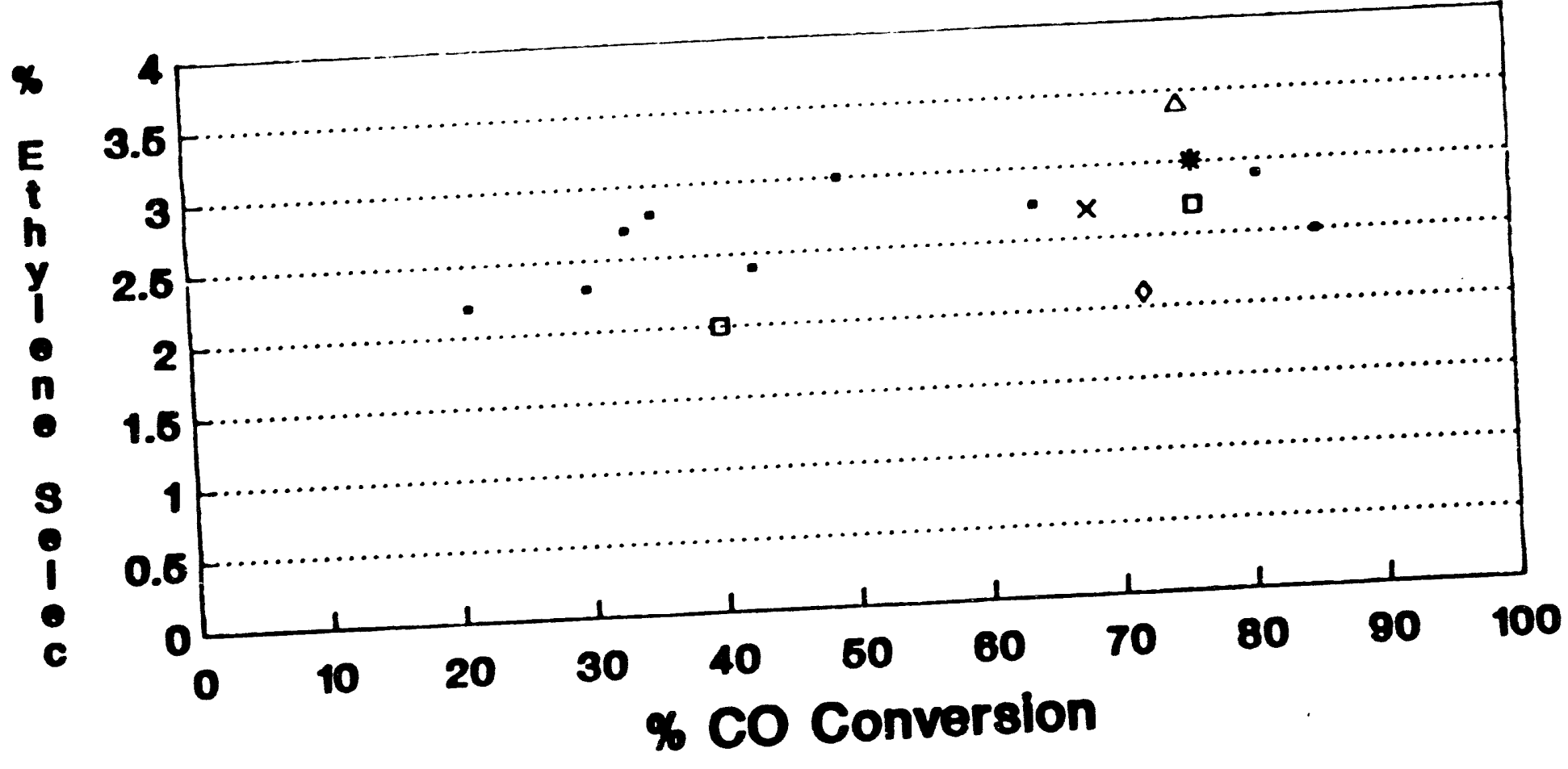

- RUN 48

$\times \quad$ RUN 47
* RUN 87

- AUN 40
D $\quad$ RUN 40

$\triangle \quad$ RUN 62 

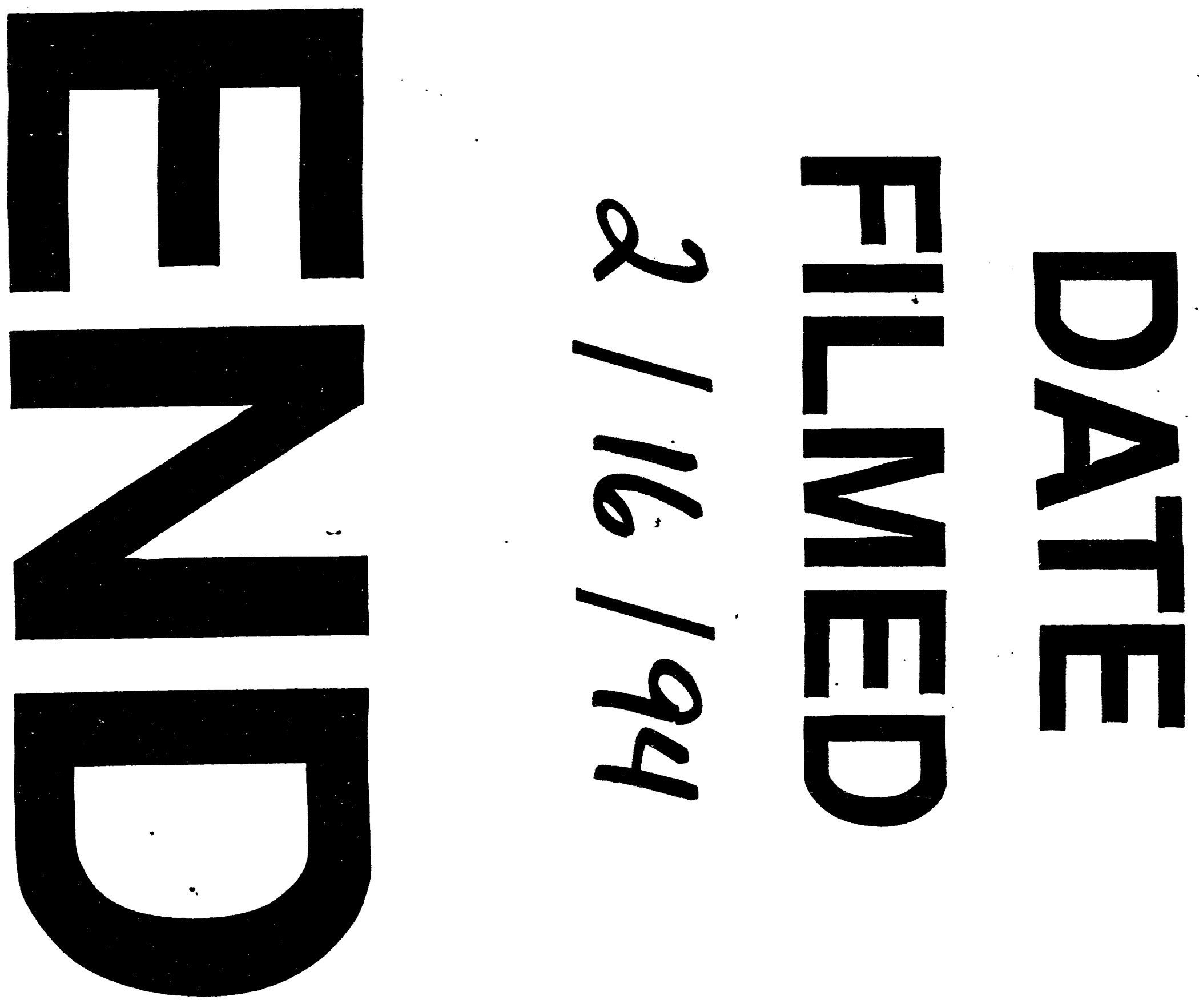
$\Omega$

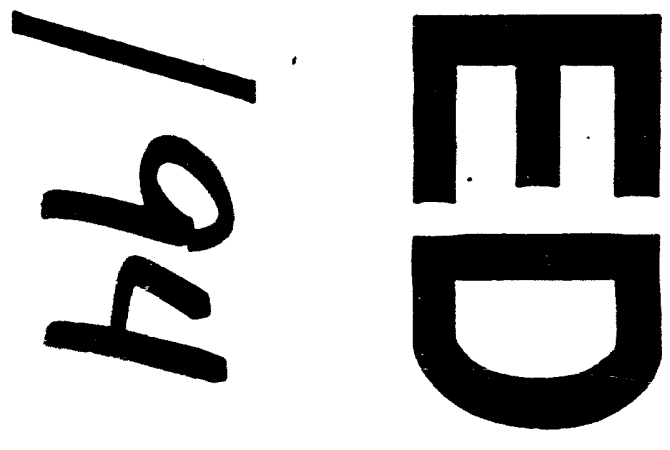


$$
\longrightarrow
$$ \\ $\longrightarrow-1-1-1$

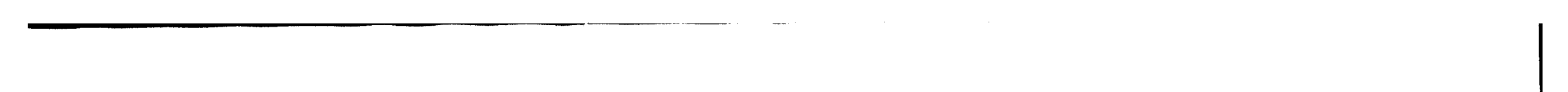

